Florida International University

FIU Digital Commons

$11-15-2019$

\title{
Utilizing Multi-Criteria Analysis and Analytical Hierarchy Process to Facilitate Everglades Restoration Decision-Making
}

Chloe C. Vorseth

Florida International University, cvors002@fiu.edu

Follow this and additional works at: https://digitalcommons.fiu.edu/etd

Part of the Agricultural and Resource Economics Commons, Environmental Policy Commons, and the Environmental Studies Commons

\section{Recommended Citation}

Vorseth, Chloe C., "Utilizing Multi-Criteria Analysis and Analytical Hierarchy Process to Facilitate Everglades Restoration Decision-Making" (2019). FIU Electronic Theses and Dissertations. 4313. https://digitalcommons.fiu.edu/etd/4313

This work is brought to you for free and open access by the University Graduate School at FIU Digital Commons. It has been accepted for inclusion in FIU Electronic Theses and Dissertations by an authorized administrator of FIU Digital Commons. For more information, please contact dcc@fiu.edu. 


\section{FLORIDA INTERNATIONAL UNIVERSITY}

Miami, Florida

\section{UTILIZING MULTI-CRITERIA ANALYSIS AND ANALYTICAL HIERARCHY PROCESS TO FACILITATE EVERGLADES RESTORATION DECISION-MAKING}

A thesis submitted in partial fulfillment of

the requirements for the degree of

MASTER OF SCIENCE

in

ENVIRONMENTAL STUDIES

by

Chloe' Vorseth 
To: Dean Michael R. Heithaus

College of Arts, Sciences and Education

This thesis, written by Chloe' Vorseth, and entitled Utilizing Multi-Criteria Analysis and Analytical Hierarchy Process to Facilitate Everglades Restoration Decision-Making, having been approved in respect to style and intellectual content, is referred to you for judgment.

We have read this thesis and recommend that it be approved.

$\begin{array}{r}\hline \text { Elizabeth Anderson } \\ \hline \text { Leonard Scinto } \\ \hline \text { Andrew Stainback } \\ \hline \text { Mahadev Bhat, Major Professor }\end{array}$

Date of Defense: November 15, 2019

The thesis of Chloe' Vorseth is approved.

Dean Michael R. Heithaus
College of Arts, Sciences and Education

Andrés G. Gil Vice President for Research and Economic Development And Dean of the University Graduate School

Florida International University, 2019 


\section{DEDICATION}

The following thesis is dedicated to my parents Mary and Eric Vorseth, and my brother Seth Vorseth. Thanks to their unwavering support since the very beginning, I am on the way to pursuing my dreams achieving my career goals. Big thanks to them for always instilling the values of compassion, care, and humor in every life situation. 


\section{ACKNOWLEDGMENTS}

I would first like to thank my advisors Dr. Andrew Stainback and Dr. Mahadev Bhat and my committee members Dr. Elizabeth Anderson and Dr. Leonard Scinto for their constant support and assistance throughout this research. Thanks to opportunities presented by Dr. Stainback, I was able to move to Miami from my hometown of Louisville, Kentucky and pursue my graduate career. I am truly touched to be included in this interesting and impactful research funded by The Everglades Foundation. Special thanks to Dr. Bhat for agreeing to take me on as a graduate student, and for always keeping me grounded throughout the research process.

I would also like to thank the staff at The Everglades Foundation for welcoming me into their offices with open arms, and for supporting my research for the past two years. Working in the same hallway as the science team at The Everglades Foundation has especially inspired me to think beyond the traditional bounds of academic research. Special thanks to Loren, Bianca, Jessica, and Keely for welcoming me into spirited lunchroom debates, celebrations, and dog birthday parties. Additionally, I would like to thank all my peers at Florida International University in the Agroecology Lab. I am especially grateful to Anna Fache and Nicholas Charles for their constant support and inspiring example as brilliant scientists and friends. Thank you to my friends at The Everglades Foundation and FIU for turning Miami into a home.

Special thanks to my friends from Kentucky for supporting my decision to move to Miami for graduate school from the very start. Finally, I would like to thank my boyfriend Dane and my dog Gandalf for providing a loving and supportive home-awayfrom-home in Miami. 


\begin{abstract}
OF THE THESIS
UTILIZING MULTI-CRITERIA ANALYSIS AND ANALYTICAL HIERARCHY PROCESS TO FACILITATE EVERGLADES RESTORATION DECISION-MAKING

by

Chloe' Vorseth
\end{abstract}

Florida International University, 2019

Miami, Florida

\title{
Professor Mahadev Bhat, Major Professor
}

Greater Everglades Ecosystem (GEE) restoration is a complex undertaking, with a variety of potential outcomes and trade-offs impacting numerous stakeholders. My study utilizes a strategy for facilitating GEE restoration that is grounded in social science principles and informed by stakeholder opinion, ecologists, and biological modeling techniques.

Information in the present study was gathered through the use of an online survey involving stakeholder preferences for GEE restoration outcomes. Results revealed that sample stakeholders weighed the outcome of improving seasonal flow of water highest, followed by reducing polluted discharges from Lake Okeechobee, then increasing water storage for human use, and lastly restoring the GEE to improve resiliency to hurricane storm surge. Additionally, the survey collected information on stakeholders' environmental attitudes. Results revealed that most stakeholders surveyed across many interests identified as "ecocentric" rather than "anthropocentric." These results have the potential to inform GEE restoration decision-making by providing a strategy to effectively combine the separate interests of each ideologically divergent stakeholder group with projected physical impacts of restoration alternatives. 


\section{TABLE OF CONTENTS}

CHAPTER

PAGE

CHAPTER 1: INTRODUCTION 1

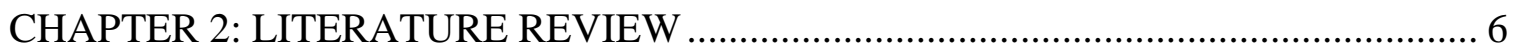

2.1 THE GREATER EVERGLADES ECOSYSTEM: RESTORATION, STAKEHOLDERS, AND MANAGEMENT ........................................................ 6

2.1.1 THE GREATER EVERGLADES ECOSYSTEM ................................... 6

2.1.2 EVERGLADES RESTORATION ....................................................... 8

2.1.3 MAJOR CHALLENGES TO EVERGLADES RESTORATION .................. 10

2.1.4 EVERGLADES RESTORATION STAKEHOLDERS ............................... 12

2.1.5 ADAPTIVE MANAGEMENT IN THE GREATER EVERGLADES

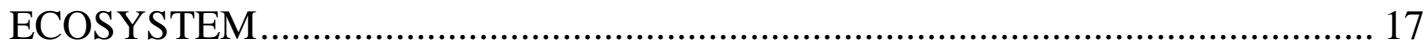

2.2 MULTI-CRITERIA DECISION ANALYSIS AND ANALYTICAL HIERARCHY PROCESS: THEORY AND APPLICATIONS ............................... 18

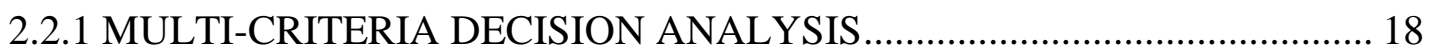

2.2.2 ANALYTICAL HIERARCHY PROCESS ................................................ 20

2.2.3 PERFORMING ANALYTICAL HIERARCHY PROCESS USING ONLINE SURVEYING TOOLS ..................................................................... 22

2.3 NEW ECOLOGICAL PARADIGM: THEORY AND APPLICATIONS ............. 23

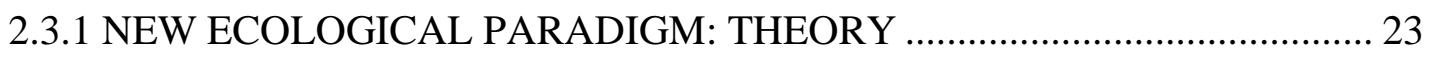

2.3.2 APPLICATIONS OF THE NEW ECOLOGICAL PARADIGM SCALE...... 26

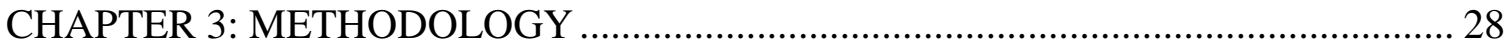

3.1 RESEARCH QUESTION 1: WHAT ARE THE MOST IMPORTANT OUTCOMES OF EVERGLADES RESTORATION TO STAKEHOLDERS? ......... 28

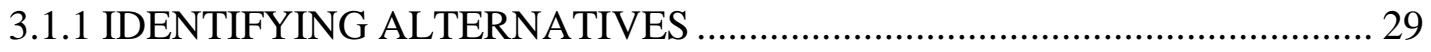

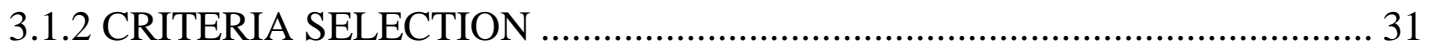

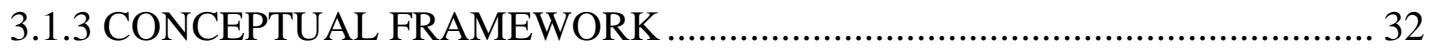

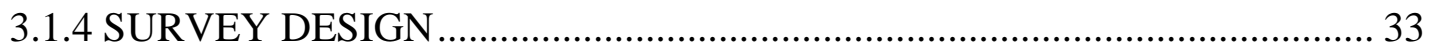

3.1.5 STAKEHOLDER IDENTIFICATION .................................................... 40

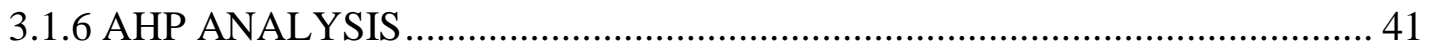

3.2 RESEARCH QUESTION 2: WHAT ARE THE PREFERENCE

DIFFERENCES BETWEEN STAKEHOLDERS? ............................................. 43 
3.3 RESEARCH QUESTION 3: WHICH FACTORS INFLUENCE

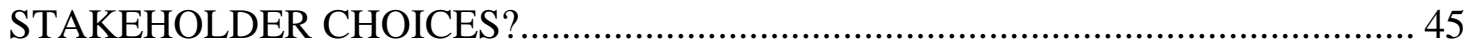

3.3.1 REGRESSION ANALYSIS ........................................................................ 45

3.4 RESEARCH QUESTION 4: WHAT ARE THE ENVIRONMENTAL ATTITUDES OF STAKEHOLDERS?

3.5 RESEARCH QUESTION 5: HOW CAN PREFERENCE STRUCTURES OF DIFFERENT STAKEHOLDERS INFLUENCE SELECTION OF

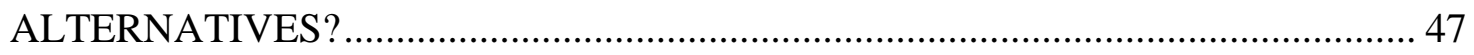

3.5.1 MULTI-ATTRIBUTE VALUE THEORY ................................................. 48

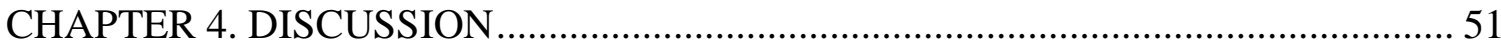

4.1 WHAT ARE THE MOST IMPORTANT OUTCOMES OF EVERGLADES RESTORATION TO EVERGLADES RESTORATION STAKEHOLDERS? ............... 51

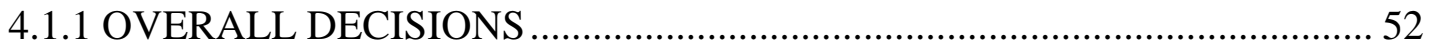

4.1.2 STAKEHOLDER GROUP DECISIONS .................................................. 53

4.2 WHICH FACTORS MOTIVATE STAKEHOLDER DECISIONS? .................... 55

4.2.1 DEMOGRAPHIC CHARACTERISTICS OF THE SAMPLE ......................... 56

4.2.2 STATISCIAL ANALYSIS RESULTS....................................................... 57

4.3 WHAT ARE THE ENVIRONMENTAL ATTITUDES OF EVERGLADES

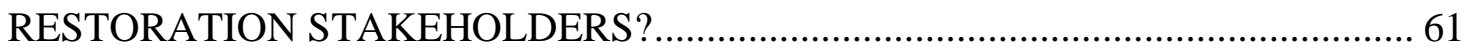

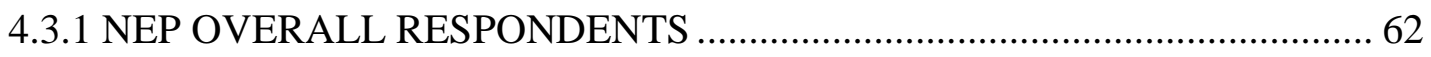

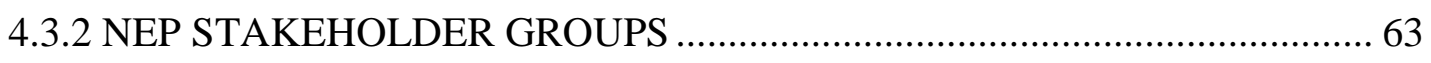

4.4 HOW CAN PREFERENCE STRUCTURES OF DIFFERENT

STAKEHOLDERS INFLUENCE SELECTION OF ALTERNATIVES? ....................65

4.4.1 MULTI-ATTRIBUTE VALUE THEORY OUTCOMES................................. 65

CHAPTER 5. CONCLUSION: ADAPTIVE MANAGEMENT IN THE GREATER

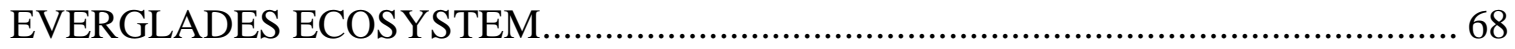

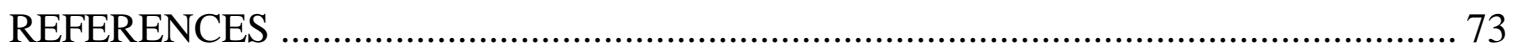




\section{LIST OF TABLES}

TABLE

PAGE

Table 1. New Ecological Paradigm scale statements developed by Dunlap et al. in original order and wording....

Table 2. Informational statements for each criteria involved in the AHP analysis.

Table 3. The Saaty scale of AHP used to complete trade-offs (Saaty, 1990), and the modified scale used by this survey with the intention of improved consistency

Table 4. Trade-off comparisons used to calculate criteria weights in table form.

Table 5. Reduction in polluted discharges from Lake Okeechobee as a result of 5 different restoration alternatives.

Table 6. Physical increase in indicator species populations as a result of 5 different restoration alternatives based on average of four different species. ............................ 50

Table 7. Consistent responses after Analytical Hierarchy Process ................................ 52

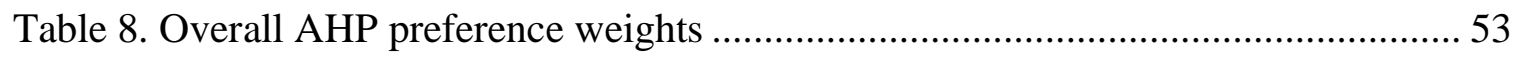

Table 9. AHP Preference Weights for Individual Stakeholder Groups ......................... 54

Table 10. Average NEP scores of each stakeholder group.......................................... 61

Table 11. Normalized values of physical impacts of each restoration alternatives.......63

Table 12. MAVT Weights of each restoration alternative based on increases in indicator species populations in Everglades National Park and decreases in polluted discharges from Lake Okeechobee. ...................................................66 


\section{LIST OF FIGURES}

FIGURE

PAGE

Figure 1. Basic conceptual framework of multi-criteria decision analysis.................... 20

Figure 2. Conceptual framework for this AHP analysis populated with the decision criteria and alternatives examined in this study....................................................... 32

Figure 3. Instructional statement used to explain the AHP trade-off process. ................. 36

Figure 4. Regression analysis results comparing priority weight of Discharges and other demographic, stakeholder group, and NEP scale responses.

Figure 5. Regression analysis results comparing priority weight of Flow and other demographic, stakeholder group, and NEP scale responses.

Figure 6. Regression analysis results comparing priority weight of Water and other

demographic, stakeholder group, and NEP scale responses.

Figure 7. Regression analysis results comparing priority weight of Hurricanes and other

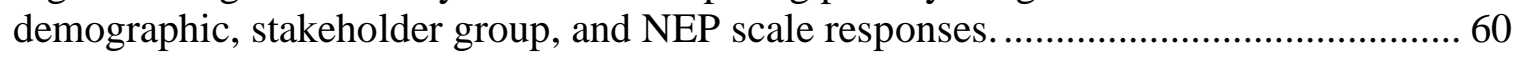

Figure 8. Seemingly Unrelated Regression analysis using small sample adjustment ...... 62

Figure 9. Distribution of NEP scores in the sample of stakeholders. .................62 


\section{UTILIZING MULTI-CRITERIA ANALYSIS AND ANALYTICAL HIERARCHY PROCESS TO FACILITATE EVERGLADES RESTORATION DECISION-MAKING}

\section{CHAPTER 1: INTRODUCTION}

On a global scale, the deep reciprocal connections between human actions and the natural world are becoming increasingly clear. While study of the ecological processes that drive natural systems is important and relevant to solving emerging environmental problems, translation of research to inform actual policy is often limited. Calls have emerged from researchers in the ecological realm for increased use of improved decisionmaking techniques, integrating transdisciplinary strategies to solve human-environmental issues holistically (Liu et al., 2007; Alberti et al., 2011). Adaptive management is one such strategy that may result in timely decision-making through both trial-and-error processes of experimentation and transdisciplinary approaches to understand trade-offs of complex ecological problems (Gunderson, 2001; Holling, 2017). Adaptive management remains largely theoretical and difficult to apply to management decisions, but is still widely considered as one of the most comprehensive methods for managing ecological systems in conjunction with the interests of human stakeholders (Allen et al., 2011).

The Greater Everglades Ecosystem (GEE) represents one such human-ecological system that was previously degraded as a direct result of human action. Over the course of a single century, human-caused redistribution of water flow disrupted the natural ecological processes in the GEE that had been constant for millennia (Sklar et al., 2005). The Comprehensive Everglades Restoration Plan (CERP), a federal and state-funded effort with a concrete timeline and project implementation plan, was passed in 2000 . The 
CERP includes projects to tackle issues related to quality, quantity, timing and distribution of water flow through the GEE, while also ensuring water supply for South Florida residents into the future (Perry, 2004).

Everglades restoration has a reputation for being an equally ambitious and complicated undertaking. The CERP was founded on the transdisciplinary ideals of adaptive management, but little connection exists between ecological and social analysis of the GEE (Gunderson \& Light, 2006). While biological, chemical, and geological evidence reporting provides sufficient justification for Everglades restoration decisionmaking and action from an ecological point of view, restoration efforts remain stagnant and timelines for restoration efforts have been extended. The greatest cause of this delay is not the lack of scientific understanding of the GEE, but the sociopolitical relationships and power dynamics between Everglades restoration stakeholders and decision-making institutions (Sklar, et al., 2005; Ogden, 2008). To adhere to the holistic ideals of CERP and adaptive management, the need for understanding of stakeholder perspectives from a combined ecological and social science point of view is urgently needed.

Because of the complex and geographically large scope of Everglades restoration, stakeholders represent an ideologically diverse sample of individuals with varying degrees of decision-making power. The South Florida Ecosystem Restoration Task Force (SFERTF), made up of 14 members representing tribal, state, federal, and local interests, is assigned with coordinating restoration efforts (Heikkila \& Gerlak, 2005). However, the inter-agency group does not include core stakeholders such as representatives from environmental advocacy groups, the agricultural sector, business leaders, and members of the academic community. While inclusion of all stakeholder groups in regulatory bodies 
such as the SFERTF is not realistically feasible, powerful stakeholders outside of regulatory bodies have historically stalled restoration efforts by years (Scarlett, 2013).

The present research was conducted to identify preferences of Everglades restoration stakeholders, as well as potential motivations for those preferences. The thesis is guided by the following objectives:

1. To identify the most important overarching criteria, or benefits, of Everglades restoration.

2. To weigh criteria based on stakeholder input with the application of the analytical hierarchy process (AHP).

3. To assess how demographic factors and environmental attitude influence stakeholder preferences.

4. To draw policy conclusions about Everglades restoration decision-making with application to real restoration scenarios.

The first and second parts of the research utilize a multi-criteria analysis (MCA) survey to quantify stakeholder preferences for specific restoration benefits. Through a rigorous process of synthesizing main outcomes of CERP, GEE restoration literature, and technical expert consultation, four overarching potential benefits of GEE restoration were identified. These benefits were then weighed through a series of trade-offs in a process called analytical hierarchy process (AHP). The resulting weights revealed those restoration benefits that are most important to Everglades restoration stakeholders, as well as the relative importance of each criteria in the decision-making process.

The third part of the research uses regression analysis to understand potential motivations for trade-off responses. Among those factors analyzed for significance is the 
use of a New Ecological Paradigm (NEP) survey to quantify the ecological attitudes of stakeholders. An environmental attitude "score" was calculated through responses to a series of 15 commonly asserted environmental attitude statements. The score was also useful when viewing the environmental attitudes of stakeholders within specific groups. Additionally, demographic information, attitudes towards CERP restoration, and open response questions regarding largest challenges to CERP implementation were also collected to aid in statistical analysis as well as to gain a detailed informational profile of individual stakeholders.

The fourth part of my research involves identifying policy implications, including application to outcomes of actual CERP projects through the use of multi-attribute value theory (MAVT). MAVT combines the normalized physical values of each benefit of GEE restoration for each potential restoration alternative to be compared to benefits most preferred by a diverse group of stakeholders. The outcome of the MAVT has the ability to reveal which restoration alternative provides the most benefits based on physical and measured variables.

Using an approach that is grounded in both current scientific knowledge of the GEE and social science tools, the present thesis seeks to understand the differences and unifying similarities expressed by a wide variety of Everglades restoration stakeholders not traditionally included in directly making GEE restoration decisions. Measurement of stakeholder preferences coincides with calls for GEE restoration decision-makers to integrate collaborative adaptive management among a variety of stakeholders into decision-making (Gunderson \& Light, 2006; Scarlett 2013). While stakeholder dynamics pose a major hurtle to implementation of CERP, use of the AHP and MAVT shows that 
illustrating restoration preferences of all stakeholders will ensure that future decisionmaking is grounded in more realistic conditions of the human social, political, and economic system.

The methodology described serves as an example for researchers and decisionmakers in any existing coupled human-environmental system interested in integrating use of collaborative adaptive management. Using transdisciplinary approaches to solve complex ecological problems, the relationships and feedbacks between human and natural systems can be more effectively understood. Additionally, the innovative application of multi-criteria analysis to an online platform has the potential to promote inclusion of more stakeholders in decision-making processes than ever before. 


\section{CHAPTER 2: LITERATURE REVIEW}

\subsection{THE GREATER EVERGLADES ECOSYSTEM: RESTORATION,}

STAKEHOLDERS, AND MANAGEMENT

\subsubsection{THE GREATER EVERGLADES ECOSYSTEM}

The Everglades is a subtropical wetland located in Southern Florida in the United States of America. For approximately 5,000 years, freshwater flowed from the Kissimmee River Basin into Lake Okeechobee, located in central Florida. During the rainy season, the southern edge of Lake Okeechobee would feed into the central Everglades in a slow, shallow sheet flow of freshwater. Over the course of months, the freshwater would feed into Florida Bay, forming an estuary system. The flow of water from the Kissimmee River, to Lake Okeechobee, through the central and southern Everglades wetland, and into Florida Bay formed a larger watershed now known as the Greater Everglades Ecosystem (GEE), encompassing 10,890 square miles (Light \& Dineen, 1994). Like any other wetland, life in the central and southern Everglades was predominantly dictated by and dependent on the seasonal quantity and timing of water flow through the system. In its "pre-drainage" condition, the GEE was perceived by many early explorers and colonizers as an unforgiving wasteland (Grunwald, 2006).

In the late 19 th and early 20 th centuries, South Florida became viewed by real estate developers and agricultural interests as a potential site for agricultural and urban development (Grunwald, 2006). Agricultural operations began on the nutrient-rich area located south of Lake Okeechobee, unknowingly causing rampant soil erosion and disruption of the natural flow of water to the wetlands located to the south (Sklar et al., 2005). After a devastating hurricane in the early nineteen hundreds, a series of earthen 
dams were constructed, permanently blocking freshwater flow from Lake Okeechobee to the Everglades (Gunderson et al., 1995). High elevation areas of present-day Miami-Dade and Broward counties containing pine rocklands, mangroves, and coral reef deposits were developed for human settlement. Over time, the natural flow of freshwater became completely controlled by a complex series of canals, dams, and locks to protect human interests from flooding events and to provide the rapidly increasing population with water (Ogden, 2008).

At the dawn of the 21 st century, approximately $70 \%$ less water flowed through an unrecognizable GEE (Perry, 2003). As a result of channelization and impoundment efforts in the 1960s and 70s (Toth, 1993; Koebel \& Bousquin, 2014), along with nutrient flow from dairy and cattle farms to the north (Perry, 2003), the ecological diversity of the Kissimmee River basin was significantly altered and reduced. Lake Okeechobee became both a water and nutrient reservoir, containing excess phosphorus and nitrogen from surrounding agricultural, urban, and industrial practices (Anderson \& Flaig, 1995; Havens \& Gawlick, 2005). To further protect agricultural land south of Lake Okeechobee from flooding, water was diverted through the channelized and impounded Caloosahatchee and St. Lucie rivers (Barnes, 2005; Sime, 2005). Both estuary systems experienced excess nutrient inundation, contaminant inundation, and altered water flow regimes, causing changes in ecological diversity and harmful algal blooms (Barnes, 2005; Sime, 2005). A significantly reduced portion of nutrient-laden freshwater still flowed south into the Everglades, but caused changes in plant assemblages, replaced longstanding hydrological cycles with cycles of flood and drought, and dramatically altered nutrient availability (Sklar et al., 2005). As a result of reduced and nutrient-laden 
freshwater flow from the southern Everglades, Florida Bay experienced spikes in salinity and algal blooms, followed by seagrass die-offs and ecosystem collapse (Montague \& Ley, 1993; Nuttle et al., 2000). In essence, the "pre-drainage" system was altered and halved into a degraded system whose water movement was almost exclusively controlled by man-made structures.

In direct contrast from the natural systems encompassed by the GEE, water channelization and control allowed the human population in South Florida to increase dramatically. In 1900, Miami-Dade County (including Martin, Broward, and Palm Beach counties) had around 5,000 residents (Smith, 2005). Areas that had been historically flooded as a result of unpredictable weather patterns remained dry throughout the year, paving the way for further human development through the coming century. With a growth rate of $90 \%$ every 10 years in the Southeast, and $66 \%$ in the Southwest, South Florida soon became the fourth-most populated area in the United States of America (Smith, 2005). Currently, the South Florida Water Management District (SFWMD), responsible for providing urban, agricultural, and environmental water supplies in South Florida, services 8.1 million people (SFWMD, 2019). The establishment of major agricultural, urban, suburban, and industrial land uses in South Florida has caused irreversible land alteration in much of the GEE.

\subsubsection{EVERGLADES RESTORATION}

At the turn of the millennium, the glaringly obvious ecological devastation caused by redirection of water in the GEE became a national issue. Poor water quality caused eutrophication in many parts of the GEE, triggering habitat loss and reduction in fish populations in surrounding bays and estuaries (USACE, 1999). Over 1.5 million acres 
were invaded by invasive nonnative plants, and over 1 million acres contained elevated levels of mercury (National Research Council, 2003). Additionally, the GEE contained 68 federally designated threatened or endangered species (Perry, 2003). To combat the eventual collapse of the economically, recreationally, and ecologically important South Florida ecosystems encompassed by the GEE, the state of Florida passed the Everglades Forever Act (EFA) in 1995 (FDEP, 2019). The act would be the precursor to federally funded act passed by congress in 1999 called the Comprehensive Everglades Restoration Project (CERP). Both the EFA and CERP aimed to protect the Everglades system through improvements in the timing, quantity, quality, flow and distribution of freshwater through the ecosystem, while simultaneously providing water resources for both ecological and human interests in the GEE (FDEP, 2019; Perry 2003).

At the time of its passage, CERP was known as the largest wetland restoration project in the world. Over the course of a projected timeline of 36 years, CERP would entail completion of 68 major projects to be implemented at a cost of $\$ 8$ billion (National Research Council, 2003). A large portion of these projects entailed establishment of a network of storm water treatment areas (STAs), decommissioning of water control structures, and introduction of water reservoirs to improve flood control and flow patterns to the remaining Everglades (Perry, 2003). Additional projects include invasive plant and animal management (Rodgers et al., 2012), and projects to improve water quality through reductions in nutrient inundation from the Everglades Agricultural Area (EAA) (Light, 2010). While extensive human development would prevent complete restoration of the GEE, CERP aspired to mimic the natural quality, quantity, timing and distribution of 
freshwater flow through the Everglades as closely as possible (National Research Council, 2003).

\subsubsection{MAJOR CHALLENGES TO EVERGLADES RESTORATION}

Unfortunately, the original timeline for CERP implementation would be stretched an additional 20 years and cost of implementation would increase by billions as a result of challenges associated with vague restoration goals (Hackney, 2000), the unknown future pressures of climate change and sea level rise (Pearlstine et al., 2010; Nungesser et al., 2013), and the special interests of stakeholders (Snyder \& Davidson, 1994; Sklar et al., 2005; Finkl \& Makowski, 2017). The CERP remains an incredible milestone in implementing interagency cooperation at the state, federal, and research institutional level to improve environmental conditions. However, each of these three challenges represents the realities of implementing complex long-term restoration plans in a complicated sociopolitical context.

Around $50 \%$ of the original GEE currently exists, with water flows through the system permanently changed by human influence (Sklar et al., 2005). Due to the dramatic change of the ecosystem and degree of human settlement, no true image of a "restored" Everglades exists, and clear endpoint goals of CERP are not clearly defined or identified (Sklar et al., 2005). Restoration projects will potentially be completed without clear endpoint goals, or those completed earlier in time may not match the goals of restoration projects completed later as future modeling technology improves. Additionally, the success metrics in terms of specific water delivery amounts and nutrient loading reductions for restoration are not clear and potentially nearly impossible to implement (Hackney, 2000; Sklar et al., 2005). These factors make decision-making especially 
difficult, with high levels of uncertainty in terms of future benefits of current actions (Scarlett, 2013).

While CERP was designed to solve problems understood by scientists in the late 1900s and early 2000s, climate change has since arisen and been proclaimed by some researchers as the biggest threat to Everglades restoration efforts (Pearlstine et al., 2010; Nungesser et al., 2013). Effects expected for South Florida as a result of climate change, including sea level rise (Haigh et al., 2014; Dessu et al., 2018) and salt water intrusion (Watson et al., 2010; Czajkowski et al., 2018), may pose significant hurdles to Everglades restoration efforts. CERP is founded on ideals of flexibility, allowing for adjustments to management techniques when emerging problems are discovered, and embracing more effective technology when available (Gunderson \& Light, 2006). Ecological and hydrological modeling has been used to predict the expected effects of sea level rise in South Florida under different potential climate change scenarios (Bloetscher et al., 2011; Dessu et al., 2018) However, the relative uncertainty of the effects of climate change, including changes in weather patterns and sea level rise, also makes management complex.

The most difficult challenge with Everglades restoration is that every major decision made in the implementation of CERP has substantial economic, ecological, and societal trade-offs (Sklar et al., 2005). While restoration is a technically difficult endeavor, the socioeconomic and political climate of South Florida makes decisionmaking actions especially difficult. Further complications result when individual stakeholder groups such as sugar agricultural interests hold more political power than others, delaying CERP projects because of special interests such as agriculture and real 
estate development (Snyder \& Davidson, 1994; Sklar et al., 2005; Finkl \& Makowski, 2017). While all of these challenges are significant, the best solution from a social science point of view is to understand additional information about the preferences of Everglades restoration stakeholders, to make more realistic management decisions for CERP implementation (Scarlett, 2013).

\subsubsection{EVERGLADES RESTORATION STAKEHOLDERS}

Everglades restoration has a variety of stakeholders with seemingly separate ideologies. While few stakeholders hold ultimate decision-making power, others are involved in managing for restoration, upholding water quality standards, and researching restoration recommendations. Other stakeholders have interest for financial, social, spiritual, or cultural reasons, and are also affected by Everglades restoration decisionmaking. Additionally, the pure scope of Everglades restoration places responsibilities on potentially thousands of individuals at local, state, and federal levels.

Stakeholder groups including the Army Corps. of Engineers (ACOE) at the federal level and the South Florida Water Management District (SFWMD) at the state level hold the largest amount of power in Everglades restoration (Heikkila \& Gerlak, 2005). While the ACOE is historically responsible for constructing the water control structures that caused massive changes in Everglades in the first place, its expertise in hydrological engineering is significant. The SFWMD is state-funded and charged with distributing water for environmental, residential, industrial, and agricultural use through research and hydrological modeling. As wielders of state and federal funding tasked with implementing and regulating Everglades restoration at both the state and federal level, these stakeholder groups are, on paper, the true decision-makers on restoration efforts. 
The Environmental Protection Agency (EPA) and the Florida Department of Environmental Protection (FDEP) are responsible for regulating and enforcing water quality and air standards. While many of the issues associated with GEE restoration are contributed to water quantity and delivery, an additional and equally challenging set of issues are associated with water quality (Sklar et al., 2005). Excess nutrients such as phosphorus and nitrogen from residential, urban, industrial, and especially agricultural land use are especially large challenges for Everglades restoration (Perry, 2008). Both the state and federal branches of the EPA are important for the regulation of point source and non-point source pollution in and near the GEE.

Additionally, the National Park Service (NPS), Florida State Parks (also run by the FDEP), and the U.S. Fish and Wildlife Service (USFWS), and the Florida Fish and Wildlife Conservation Commission (FWC) hold regulatory and land management power over natural, coastal, and recreational areas of the GEE. The NPS conducts research, performs restoration projects, and manages Everglades National Park and Big Cypress National Preserve, two of the only remaining natural systems in South Florida. Florida State Parks (and FDEP) are responsible for smaller land areas such as the Fakahatchee Strand State Preserve. Finally, both the USFWS and the FWC manages and enforces fishing and hunting regulations in the Florida Panther National Wildlife Refuge and the Everglades and Francis S. Taylor Wildlife Management Areas, among others. At the local level, counties such as Miami-Dade and Broward manage remaining inland and coastal remnants of the original GEE in the form of county parks, preserves, and historical landmarks. 
Tribal stakeholder groups such as the Seminole and Miccosukee tribes have an especially significant connection to historic tribal lands. After decades of abuse and war from colonists in South Florida, the Seminole and Miccosukee people were pushed onto a reservation within the GEE. Current reservation lands were not traditionally occupied by the Seminole and Miccosukee people before the arrival of colonizers but served as a refuge from colonizers who were unable or unwilling to enter the seemingly impenetrable Everglades (Grunwald, 2007). Unfortunately, the land granted to the Seminole and Miccosukee was significantly affected by the water redistribution actions of the 20 th century, with little regard for the cultural, spiritual, financial, and recreational needs of the tribe (Dussais, 2013). The environmental degradation was especially devastating, as the Seminole people view ancestral land as a synonymous extension of themselves (Cattelino, 2009). After years of litigation, the Seminole people were granted compensation for the destructive water control methods of the 20th century, also sparking the modern movement to restore the Everglades (Dussais, 2013). As a result of this close connection to the ecological quality of the land, the Seminole people also contribute to Everglades restoration through regulation of water quality standards as an extension of the Clean Water Act (Dussais, 2013).

Researchers at the university, state, and federal level also hold a significant role in Everglades restoration, as intimate knowledge of Everglades restoration is necessary for informed decision-making (Gunderson \& Light, 2006). At the university level, Florida International University, the University of Florida, Florida Gulf Coast University, and Florida Atlantic University all have Everglades research groups. Additionally, countless other university researchers at the graduate, post-doctoral, and professorial level conduct 
research that effectively contributes to Everglades restoration and knowledge of current conditions in the GEE. At the federal level, the United States Geological Survey (USGS) and the National Oceanic and Atmospheric Administration (NOAA) perform research and collect publicly available long-term data for use by the research community.

Environmental organizations and advocacy groups represent stakeholders who dedicate time and effort to speaking for the voiceless natural areas within the GEE (Light \& Dineen, 1994). Nationally recognized organizations include the Sierra Club, Greenpeace, and the Audubon Society, while local organizations include The Everglades Foundation, the Everglades Coalition, and "Friends" of various specific parts of the GEE. In some cases, the Audubon Society holds a land management role with connections to water movement decision-making, as seen in the Corkscrew Swamp Sanctuary near Naples, Florida (Bancroft et al., 1988). These stakeholders, usually made up of environmentalists, are usually engaged in advocating for CERP implementation at the local, state, and federal level.

Both directly and indirectly, the business community at large encompassed by the GEE is also a stakeholder in Everglades restoration, especially in regard to the tourism, recreational, and real estate industries. In an economic valuation study, the ecosystem services provided by the GEE totaled at over $\$ 16$ billion in benefits for real estate, over \$1 billion for park visitation, over \$520 million for commercial fishing, and over \$2 billion for recreational angling (Mather Economics, 2010). The ecological health of the GEE has close connections with all of these industries, as seen in the economic impacts of reduced recreational angling conditions in Florida Bay (Stainback, 2018) and Everglades National Park (Brown et al., 2018), as well as the economic impacts of 
harmful algal blooms on real estate markets (Wolf \& Klaiber, 2017). While stakeholders in the business community may not have scientific knowledge of the GEE, they are linked to decision-making through economic costs and benefits of decisions.

Alternatively, agricultural interests in the Everglades Agricultural Area (EAA) pose a significant physical and political barrier to the flow of water from Lake Okeechobee to Everglades National Park (Ogden, 2008; Finkl \& Makowski, 2017). Unlike many of the other stakeholders with either managerial, financial, cultural, or ethical interests in the completion of Everglades restoration, the implementation of CERP would ultimately eliminate longstanding agricultural practices in the EAA. However, soil erosion and soil quality concerns are rapidly posing challenges to the validity of the EAA as suitable agricultural land (Snyder \& Davidson, 1994; Sklar, 2005). While some individual farmers in the EAA with generational ties to the area exist, the majority of the area is occupied by large corporations. With powerful political ties and lobbying power, industrialized agricultural practices connected to the economically valuable sugar industry have the ability to delay restoration projects advocated by the scientific community (Snyder \& Davidson, 1994). Integration of the preferences of the agricultural community in the EAA is essential for the sweeping vision of CERP to come to fruition.

Lastly, the human population of over eight million people dependent on the GEE for industrial, residential, and agricultural water supply also represent a significant stakeholder group (SWFMD, 2019). The group is the furthest removed from the other stakeholder groups, as many residents are not informed of the benefits provided by the GEE essential to day-to-day life. 
While all the listed stakeholders have varying degrees of interest and power over Everglades restoration decision-making, all are affected in some way. While the SFERTF is tasked with coordinating Everglades restoration efforts, only representatives from federal, state, and local government and tribal interests are included (Heikkila \& Gerlak, 2005). While the SFERTF group is essential for guiding GEE restoration decision making and the implementation of CERP and represent major stakeholders, other restoration stakeholders such as agricultural interests in the EAA can delay restoration efforts. Additionally, some stakeholders, including Everglades researchers, the business community, the agricultural community, or local advocacy groups are often not included in decision-making. To ground decision-making in a more realistic context, the restoration preferences of stakeholders must be investigated through a deliberative process (Scarlett, 2013).

\subsubsection{ADAPTIVE MANAGEMENT IN THE GREATER EVERGLADES ECOSYSTEM}

To combat challenges with Everglades restoration both foreseen and unforeseen, CERP is loosely grounded in principles of flexibility and experimentation through passive adaptive management (Gunderson \& Light, 2006). To remain relevant to incoming challenges, adaptive management expressly depends on uncertainty as a constant driving force of hypothesis formation, experimentation, management action and reevaluation (Gunderson, 2001). While ecological understanding of the GEE is indeed constantly evolving through the processes of scientific monitoring and research with a thriving research community, discoveries made by scientists are often considered irrelevant to realistic sociopolitical conditions (Scarlett, 2011). As a result of the 
disconnect, sociopolitical and socioeconomic challenges are often not considered when researching and modeling CERP implementation (Scarlett, 2011). The social, institutional, and political processes that dictate decision-making in the GEE should be integrated into the scientific experimentation process, so that cycles and feedbacks between societal decision-making and ecological systems are exposed (Liu et al., 2007).

Deep ideological differences between special interests in Everglades restoration, including agricultural and real estate interests, impede the progress of restoration at every turn (Gunderson \& Light, 2006). To facilitate effective adaptive management to restore the GEE, all stakeholders, even those with the ability to oppose restoration, should be included in the restoration planning process from the very beginning (Gunderson \& Light. 2006; Scarlett, 2013). The present thesis seeks to integrate all stakeholders into the decision-making process through commonly used social science tools grounded in ecological understanding of the GEE.

\subsection{MULTI-CRITERIA DECISION ANALYSIS AND ANALYTICAL HIERARCHY PROCESS: THEORY AND APPLICATIONS}

\subsubsection{MULTI-CRITERIA DECISION ANALYSIS}

Multi-criteria decision analysis (MDCA) is a faction of social sciences that can be applied to decision-making in nearly every field at any scale, from deciding which house to purchase to implementing national security measures (Saaty, 1990; Chang 1997). In the environmental realm, complex decisions arise when dealing with management issues such as emissions standards, water and air quality management, waste management, sanitation technology, ecosystem restoration, and stakeholder dynamics (Huang et al., 2011; Linkov \& Moberg, 2011; Seleman and Bhat, 2016). As a consequence of the 
combination of environmental stressors and a large number of ideologically different stakeholders, the GEE represents an especially complex management challenge. Additionally, large-scale decision-making can have diverse impacts on any number of stakeholders, ultimately stalling decision-making timelines of restoration efforts.

The MCDA method assists with the decision-making process by dividing one large decision into main criterion, and then choosing which criterion is most important (Dodgson et al., 2009; Mateo, 2012). Additionally, alternatives to the decision are analyzed in terms of measurable outcomes, each representing a unique assemblage of criteria. In doing so, those decision-making alternatives that maximize the benefits to prioritized criteria represent decisions that provide the most benefits to either implementation of a specific plan overall, or to stakeholders involved in the MCDA process.

Nearly all MCDA methods follow the same basic process of first identifying alternatives to decision-making, then identifying potential criteria for the alternatives to the decision, then weighing the differences between criteria, and finally using the resulting weights to compare alternatives (Triantaphyllou, 2000). The conceptual framework is visualized in Figure 1. To ensure that the MCDA can be applied to realistic situations, decision-making alternative selection should be completed with consultation from experts or the literature, with direct application to specific existing choice alternatives (Dodgson et al., 2009). Similarly, criteria selection should reflect measurable outcomes of the alternatives, which can later be compared to the resulting weights (Dodgson et al., 2009). While these are the core elements of MCDA, a number of 
strategies exist to complete the final weight and analyzation steps based on the management situation at hand.

Figure 1. Basic conceptual framework of multi-criteria decision analysis (Source: Saaty \& Vargas, 2012).

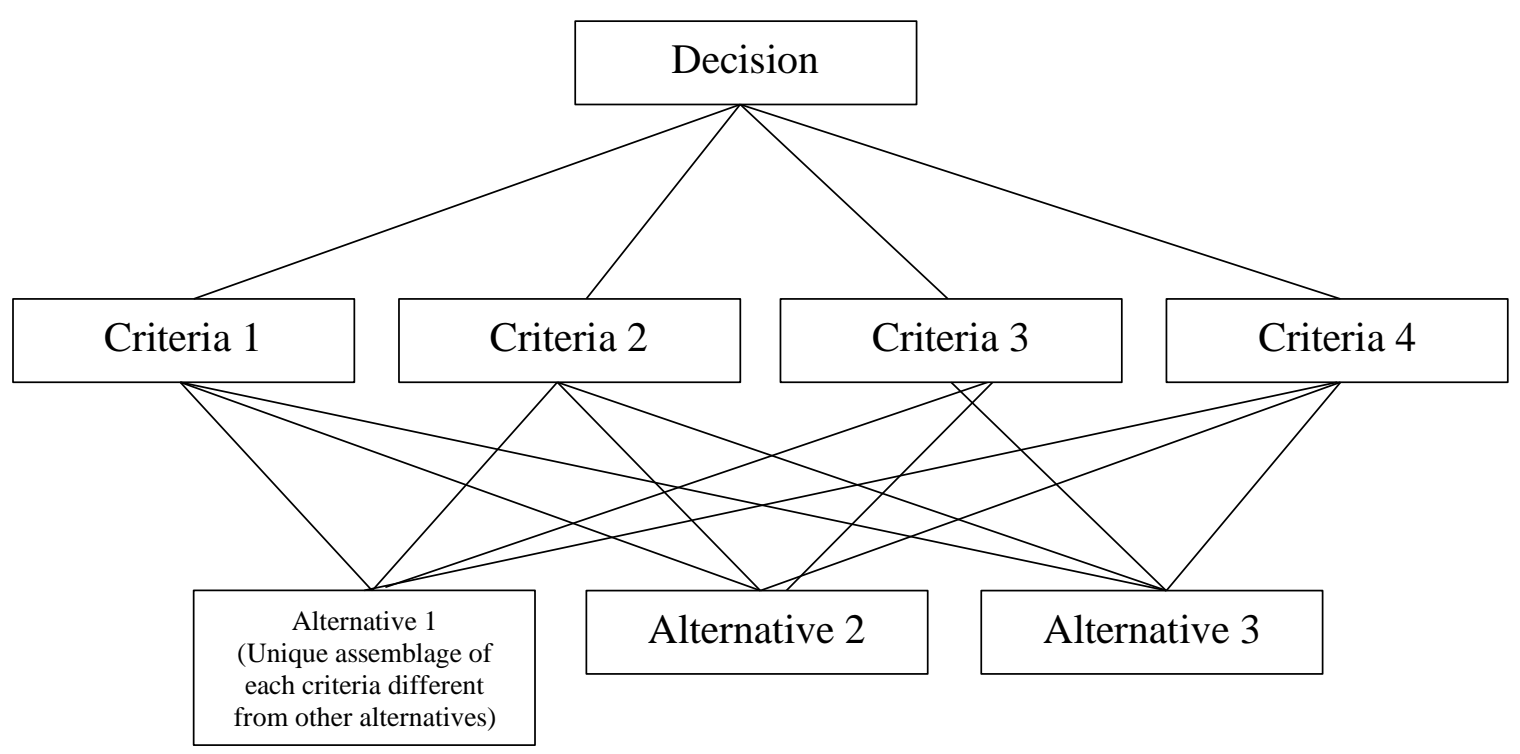

\subsubsection{ANALYTICAL HIERARCHY PROCESS}

While a number of strategies exist for completion of MDCA, the Analytical

Hierarchy Process (AHP) method is most relevant for use on evaluating stakeholder decision-making (Schmoldt et al., 2013). In applications where decision-making is dependent on input from a larger group, the AHP has the ability to capture a variety of individual and group standpoints (Saaty \& Peniwati, 2013). Additionally, instead of displaying all potential criteria at once for ranking and weighing, the AHP utilizes an indirect method to more effectively understand comparative weights of each criteria (Dodgson et al., 2009). 
The use of AHP is also functional because it reveals not only the most important criterion for decision-making, but also how much more important each criterion is in relation to others (Zahedi, 1986). Respondents, including stakeholders or a panel of experts in some cases, make pairwise comparisons between identified criteria, which then undergoes an algebraic matrix analysis to reveal the comparative weights of each criteria (Saaty, 1978, 1990). Since its creation, AHP has become one of the most commonly used strategies for public and private environmental managers and has been applied to several management decisions with potential social, economic, and environmental outcomes (Kiker et al., 2005, Schmoldt et al., 2013).

Stakeholder input is embedded in the core framework of environmental decision making under adaptive management (Glicken, 2000; Buysse \& Verbecke, 2003) and also important to the completion of the AHP (Saaty 1978, 1981, 1990). However, application of AHP differs in the literature considerably, dependent on the application and scope of the decision at hand. Because of the complex and interconnected social, economic, and environmental outcomes of environmental decision-making, stakeholder input from governmental, industrial, agricultural, recreational, cultural, educational, and public realms is essential for both equality in decision-making input (Reed, 2008) and completion of a more holistic AHP analysis.

Public resource managers have preference for traditional AHP analysis with a high degree of stakeholder involvement and highly diverse stakeholder makeup. Decision-making in applications including forest planning (Ananda, 2003), watershed planning (Arnette, 2010; Herath, 2004), land preservation (Duke, 2002), and fisheries policy management (Mardle, 2004) involve interdisciplinary cooperation, with outcomes 
that impact a large number of diverse stakeholders with varying interests. Public resource managers also occasionally employ diverse stakeholder input for policy development purposes, including development of agricultural riparian area restoration requirements (Qureshi \& Harrison, 2001, 2003) and development of alternative energy sources (De Lange, 2012).

While public land managers particularly require diverse stakeholder input, environmentally relevant private sector management applications also strive to include diverse stakeholder consideration. Private applications in the literature include choosing solid waste disposal site locations (Contreras, 2008) and evaluating public pressure on industries to convert to green supply chains (Mathiyazhagan, 2014). Though private decision-making is ultimately completed internally, applications utilized by private industries have the benefit of gauging public perception of management decisions, and displaying ethical consciousness (Mathiyazhagan, 2014). To ensure involvement of all potentially impacted parties, public land managers, private industries, and researchers attempt to survey highly diverse representative groups.

\subsubsection{PERFORMING ANALYTICAL HIERARCHY PROCESS USING ONLINE SURVEYING TOOLS}

Historically, the analytical hierarchy process (AHP) was performed on a small group of stakeholders or experts, because of the complicated nature of completing a large number of trade-offs as well as the difficulty of convening groups in person. To combat the complications that may arise with gathering AHP recipients, a recent study revealed that the AHP can be completed using online surveying techniques (Barone et al., 2014). Online survey methods effectively decrease the overall time and costs associated with 
completing the analysis, and is able to reach geographically separated stakeholders. While the method has not been widely used in the environmental realm, applications include supply chain management in the multi-billion-dollar manufacturing industry (White \& Borchers, 2016), remote area micro-grid electricity planning (Jamal et al., 2018), and analysis of bioeconomy transitions (D'Adamo et al., 2019). Further application of the AHP in conjunction with online surveying techniques has the potential to ease the process in the future.

In the present case, AHP has been chosen to better understand which criterion are comparatively most important to GEE restoration stakeholders, how much more those criteria are preferred over others, and to identify which GEE restoration projects align with preferred criterion. As a result of the large number and geographic scope of Everglades restoration stakeholders, the process was completed online.

\subsection{NEW ECOLOGICAL PARADIGM: THEORY AND APPLICATIONS}

\subsubsection{NEW ECOLOGICAL PARADIGM: THEORY}

In addition to MCA and AHP, past studies have widely used a surveying strategy called the New Ecological Paradigm (NEP) scale to identify the environmental attitudes of stakeholders (Stern et al., 1995; Rideout et al., 2005; Dunlap, 2008). Use of the NEP allows researchers to capture a richer profile of individual survey respondents, while also allowing for analysis of underlying ideological differences between stakeholder groups.

As a result of the environmental movement started in the 1960s and 1970s, social science researchers found increasingly popular emerging ethics about relationships between humans and the environment among the general public (Drengson, 1980). In the new era of thought, referred to as the "New Ecological Paradigm", humans held 
ecocentric attitudes towards the natural environment (Dunlap, 1978; Catton \& Dunlap, 1980). These attitudes were rooted in the ideas that humans and nature had equal rights to exist on earth, and that nature had intrinsic value in addition to what it could offer to humans (Kortenkamp \& Moore, 2001). In the widely held standard era of thought, referred to as the "Dominant Social Paradigm," humans had anthropocentric attitudes (Dunlap, 1978; Catton \& Dunlap, 1980). The opposing attitude was rooted in the ideals that nature held resources meant for exploitation by humans, and that humans had the ability to challenge or conquer nature through ingenuity and technology (Kortenkamp \& Moore, 2011). Additionally, some members of the population did not fit either category, with a neutral attitude on both ecocentrism and anthropocentrism.

While all humans fall somewhere along the ecological attitude scale, simply asking survey respondents if they were "ecocentric" or "anthropocentric" did not seem to grasp the variety of environmental attitudes that could define an individual in either category. To better capture environmental attitudes, Dunlap and Van Liere (1978) developed a series of 12 statements that expressed four extreme anthropocentric statements, and eight ecocentric statements of various ethic levels, to be weighed on a Likert scale. The original scale was highly controversial, considering that respondents were confronted with an uneven number of statements from opposing attitudes, and that anthropocentric statements were considered too extreme, biasing results to reflect more ecocentric views (Hawcroft \& Milfont; 2010).

Twenty years later, an updated version of the NEP was released, including 15 alternating statements that expressed seven more diverse anthropocentric perspectives and eight ecocentric perspectives, also involving Likert-scale responses (Dunlap et al., 
2000). The updated version expressed in Table 1 is currently commonly utilized by researchers in several fields conducting political, technological, environmental, and economic studies (Dunlap, 2008).

Table 1. New Ecological Paradigm scale statements developed by Dunlap et al. in original order and wording (Source: Dunlap, 2008).

\begin{tabular}{|c|c|}
\hline Ideological View & NEP Statement \\
\hline Ecocentric & $\begin{array}{l}\text { 1. We are approaching the limit of } \\
\text { the number of people the earth can } \\
\text { support. }\end{array}$ \\
\hline Anthropocentric & $\begin{array}{l}\text { 2. Humans have the right to modify } \\
\text { the natural environment to suit } \\
\text { their needs. }\end{array}$ \\
\hline Ecocentric & $\begin{array}{l}\text { 3. When humans interfere with } \\
\text { nature, it often produces disastrous } \\
\text { consequences. }\end{array}$ \\
\hline Anthropocentric & $\begin{array}{l}\text { 4. Human ingenuity will ensure that } \\
\text { we do NOT make the earth } \\
\text { unlivable. }\end{array}$ \\
\hline Ecocentric & $\begin{array}{l}\text { 5. Humans are severely abusing the } \\
\text { environment. }\end{array}$ \\
\hline Anthropocentric & $\begin{array}{l}\text { 6. The earth has plenty of resources } \\
\text { if we just learn how to develop } \\
\text { them. }\end{array}$ \\
\hline Ecocentric & $\begin{array}{l}\text { 7. Plants and animals have as much } \\
\text { right as humans to exist. }\end{array}$ \\
\hline Anthropocentric & $\begin{array}{l}\text { 8. The balance of nature is strong } \\
\text { enough to cope with the impacts of } \\
\text { modern industrial nations. }\end{array}$ \\
\hline Ecocentric & $\begin{array}{l}\text { 9. Despite our special abilities, } \\
\text { humans are still subject to the laws } \\
\text { of nature. }\end{array}$ \\
\hline Anthropocentric & $\begin{array}{l}\text { 10. The so-called "ecological crisis" } \\
\text { facing humankind has been greatly } \\
\text { exaggerated. }\end{array}$ \\
\hline Ecocentric & $\begin{array}{l}\text { 11. The earth is like a spaceship with } \\
\text { very limited room and resources. }\end{array}$ \\
\hline Anthropocentric & $\begin{array}{l}\text { 12. Humans were meant to rule over } \\
\text { the rest of nature. }\end{array}$ \\
\hline Ecocentric & $\begin{array}{l}\text { 13. The balance of nature is very } \\
\text { delicate and easily upset. }\end{array}$ \\
\hline
\end{tabular}




\begin{tabular}{|c|c|}
\hline Anthropocentric & $\begin{array}{l}\text { 14. Humans will eventually learn } \\
\text { enough about how nature works to } \\
\text { be able to control it. }\end{array}$ \\
\hline Ecocentric & $\begin{array}{l}\text { 15. If things continue on their present } \\
\text { course we will soon experience a } \\
\text { major ecological catastrophe. }\end{array}$ \\
\hline
\end{tabular}

\subsubsection{APPLICATIONS OF THE NEW ECOLOGICAL PARADIGM SCALE}

The emerging method is currently used for estimating environmental attitudes in several fields (Dunlap, 2008), and has revealed several overarching trends. Use of the NEP has revealed trends in increasingly ecocentric environmental attitudes since the first iteration of the scale in the 1980's (Dunlap et al., 2000). Those who agree more with the anthropocentric statements are less likely to be concerned with environmental issues, while those who demonstrate environmental concern are willing to act toward solving environmental problems (Kilbourne et al., 2002). Those who take the NEP scale survey before and after environmental education modules are likely to present an ecocentric outlook after education (Rideout, 2005). Most importantly, use of the NEP scale has been proven to show correlations between political, cultural, and economic attitudes (Dunlap et al., 2000; Dunlap 2008). These discoveries show that the NEP reflects a richer picture of individual respondents, potentially revealing cultural attitudes, political attitudes, and actual willingness to support environmentally focused decision-making (Kilbourne et al., 2002).

Because of the informative power of the NEP scale, the method is used in conjunction with other surveying strategies to enrich statistical analysis and inform researchers about the specific attitudes of target groups. More specifically, the NEP has been used in conjunction with preference models throughout the literature, including 
choosing between best management practices for non-point source pollution (Du et al., 2019), evolving use of technologically efficient methods for farming in the face of climate change (Orduño Torres et al.. 2019), and preferences for alternative development in natural areas (Kaltenborn et al., 2009). In a case within the GEE, Milon and Scrogin (2004) used the NEP to understand public willingness to pay (WTP) for improvements in dryland, wetland, and marine animal species in the GEE. This WTP study revealed a fairly even distribution of both econcentric and anthropocentric viewpoints, but with slight skews toward ecocentric responses (Milon \& Scrogin, 2004). While the Milon and Scrogin survey captures the environmental attitudes of the general public in South Florida, the present thesis seeks to capture environmental attitudes of informed restoration stakeholders. 


\section{CHAPTER 3: METHODOLOGY}

The research project answered five related questions pertaining to identifying the most beneficial outcomes of GEE restoration, as well as illustrating the environmental attitudes of Everglades restoration stakeholders. These questions include:

1. What are the most important outcomes of GEE restoration to stakeholders?

2. What are the preference differences between stakeholders?

3. Which factors influence stakeholder choices?

4. What are the environmental attitudes of Everglades restoration stakeholders?

5. How can preference structures of Everglades restoration stakeholders influence decision-making?

The following methodology is divided into individually answering each research question. The predominant methods used in the section include analytical hierarchy process (AHP), simple regression analysis, new ecological paradigm (NEP), and multi-

attribute value theory (MAVT) strategies. The major focus of the research identified and quantified the restoration preferences of Everglades restoration stakeholders to aid in restoration decision-making, while collecting additional information about stakeholders. These methods can be applied to unique management challenges and situations both inside and outside of the GEE, with potential application to various GEE restoration alternatives.

\subsection{RESEARCH QUESTION 1: WHAT ARE THE MOST IMPORTANT OUTCOMES OF EVERGLADES RESTORATION TO STAKEHOLDERS?}

The analytical hierarchy process (AHP) was utilized to answer the first research question in the study. The AHP process started by identifying potential Everglades 
restoration alternatives, as well as effective criteria to portray potential restoration outcomes. An online version of the AHP was then created, involving informational statements about each criteria, a series of six pair-wise comparisons, New Ecological Paradigm (NEP) scale questions, Everglades restoration attitude questions, and demographic questions. To facilitate a collection of a wide variety of perspectives on Everglades restoration, a diverse group of stakeholders was asked to respond to the survey. Finally, AHP analysis was used to reveal the comparative preference weights of all stakeholders who responded to the survey.

Online use of the AHP in this case can be justified due to a number of factors. Firstly, the time and budgetary requirements to convene geographically spread stakeholders were outside of the scope of this research. Secondly, GEE restoration is an undertaking that involves a wide variety of stakeholders both inside and outside of governmental institutions. Use of the online survey allowed for responses to be collected anonymously. Governmental representatives and those representatives of potentially more restrictive stakeholder groups had the ability to answer questions in a space that did not collect identifying information. Thirdly, the online version of the survey allowed us to collect a larger sample of stakeholders from a variety of backgrounds. In some traditional applications of the AHP, a maximum of ten stakeholders are used for analysis. Due to the complexity of Everglades restoration, contact with a larger group of stakeholders was vital to collecting a holistic understanding of stakeholder preference.

\subsubsection{IDENTIFYING ALTERNATIVES}

As a result of the sheer number of restoration projects involved in CERP, evaluating different alternatives to CERP was beyond the scope of the present study. 
However, many individual projects in CERP have the potential to profoundly impact restoration efforts in the GEE. One such project involves construction of a water reservoir in the agricultural area south of Lake Okeechobee, also known as the Everglades Agricultural Area (EAA) Reservoir. The reservoir has the potential to alleviate polluted water discharges into the St. Lucie and Caloosahatchee estuaries, increase the seasonal flow of water south to the central and southern Everglades, and store water for multipurpose use (McLean, Ogden, \& Williams, 2002). While the reservoir would have the potential to improve water flow, water resource managers are unsure about how much water should be stored. Potential options include in million-acre-foot either a $0.24,0.5,1$, 1.5 , or 2 size reservoir, with unique outcomes on wildlife populations, water storage amounts, vegetation distribution, and reduced polluted discharges from Lake Okeechobee into the northern estuaries.

Ecological and hydrological modeling of the outcomes of the five different EAA reservoir storage amounts were provided by the science team at The Everglades Foundation. These outcomes include:

1. The ecological effects on populations of specific charismatic and indicator species including wading birds, alligators, the endangered Everglades snail kite, and seatrout.

2. The hydrological reductions in discharges from Lake Okeechobee.

3. The hydrological volumes of water stored by the reservoir for potential environmental, industrial, agricultural, and residential use.

Traditional multi-criteria analysis such as analytical hierarchy process requires coordination between decided alternatives and criteria selected to represent those 
alternatives (Saaty 1978, 1981, 1990). Criteria should be selected on the basis of measurable outcomes of alternatives, such as those provided here by The Everglades Foundation.

\subsubsection{CRITERIA SELECTION}

To evaluate the effectiveness of different restoration scenarios, major outcomes, or criteria, of the EAA reservoir had to first be identified. Due to the complexity of Everglades restoration, the variety of stakeholder interests, and recent knowledge of the emerging challenges associated with climate change, the potential pool of criteria was numerous. A priority in this process was to choose criteria that could be both projected using modeling techniques, and that were relevant to the needs of a variety of stakeholders, including those in the research, agricultural, business, and environmental advocacy communities.

Additionally, AHP involves use of pairwise comparisons between criteria to eventually provide the weights of importance to decision-making. With the addition of each criteria, the number of trade-offs required increases. With each increase in criteria comes the potential for increased trade-offs and inconsistency in decision-making, also reducing the validity of the AHP analysis. For example, four criteria would amount to a total of six trade-offs, while five criteria would amount to a total of 10 trade-offs. Due to this constraint, the research team concluded that four criteria should be the maximum number used in the AHP.

The initial list of criteria included six diverse options. Experts at Florida International University and The Everglades Foundation were consulted to narrow this list to four options. These criteria included: 
1. Reducing polluted discharges from Lake Okeechobee into the St. Lucie and Caloosahatchee river estuaries.

2. Improving seasonal flow of water through Everglades National Park into Florida Bay

3. Reducing hurricane and associated storm surge impact provided by the Everglades ecosystem.

4. Increasing freshwater supply for residential, industrial, and agricultural use.

These criteria were then integrated into an online version of the AHP analysis, using the online surveying platform Qualtrics.

\subsubsection{CONCEPTUAL FRAMEWORK}

After finalization of the restoration alternatives and the criteria involved in the AHP analysis, the conceptual framework outlined the literature review (Section 2.2.1, Figure 1) could be populated to set up for the AHP. The framework is shown in Figure 2.

Figure 2. Conceptual framework for this AHP analysis populated with the decision criteria and alternatives examined in this study.

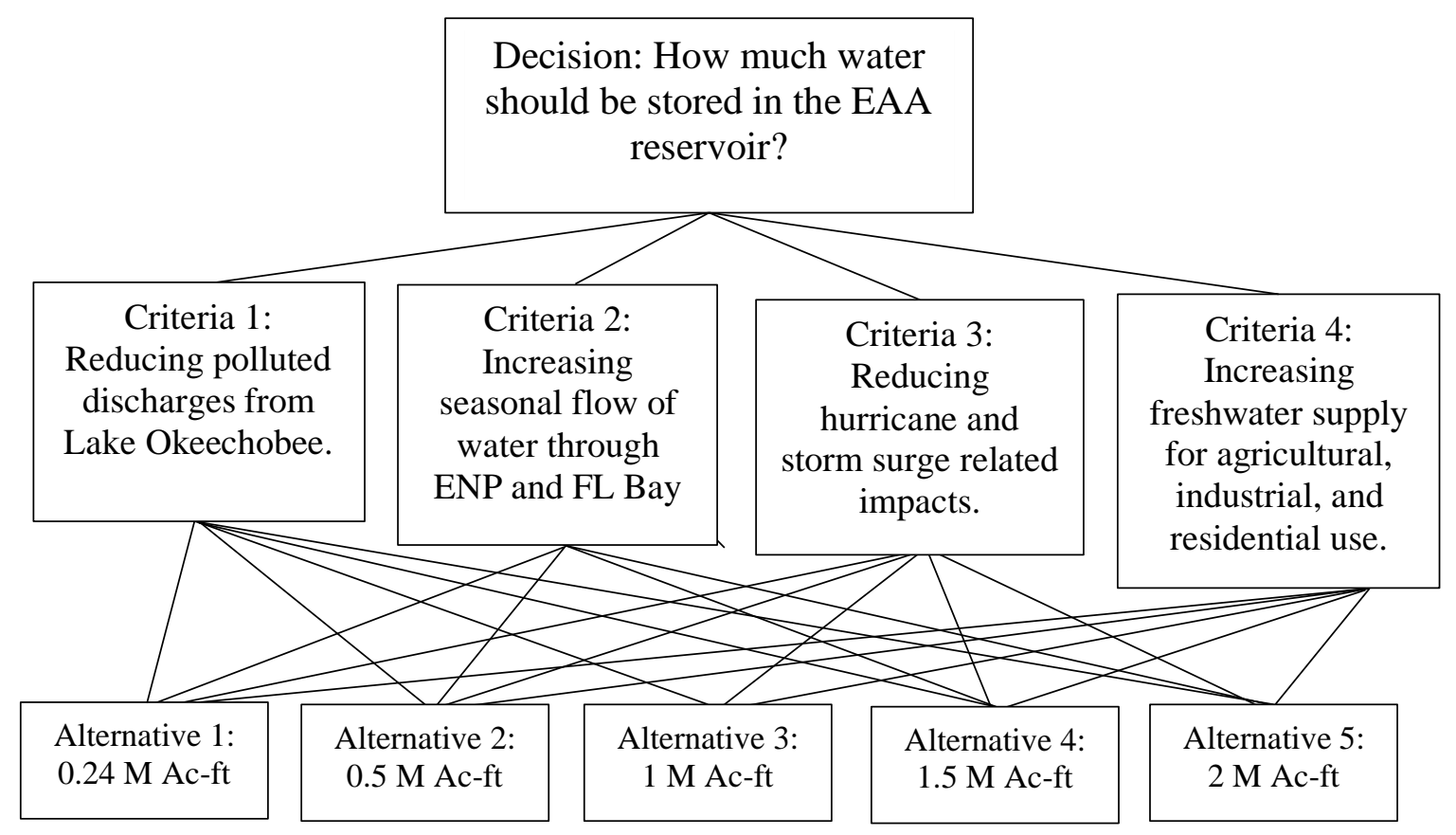




\subsubsection{SURVEY DESIGN}

To make the AHP more accessible to a wide variety of restoration stakeholders, the analysis was collected using an online version of the AHP through the surveying platform Qualtrics. The survey was broken up into six major sections, including stakeholder identification, informational statements, the AHP, the NEP, Everglades restoration attitudinal questions, and a demographic section. Each section was intentionally included to either perform the AHP in a holistic manner, or to enrich the statistical analysis regarding the motivations behind stakeholder decision-making. After survey design was established, the survey was tested on a panel of 20 individuals who provided feedback on flow, clarification of directions, and length. The following section describes each section of the online survey used to understand the most important outcomes of GEE restoration to decision-makers.

\subsubsection{STAKEHOLDER SELF-IDENTIFICATION}

The first part of the survey included self-reporting of one or multiple stakeholder groups. These potential groups included agriculture, business community, real estate, environmental organization or advocacy group, recreation/tourism industry, university professor/researcher, university graduate student, state government employee, federal government employee, county government employee, Native American tribal representative, water utility, natural resources, and other. Collection of this information was fairly important to ensure identification of specific stakeholder groups. With the information, responses to the later AHP section were traced to the associated stakeholder group. 


\subsubsection{INFORMATIONAL STATEMENTS}

To prepare the stakeholders for the AHP section of the survey, and to ensure that stakeholders understood each criterion, brief informational statements were formulated, along with informational graphics. The informational statements were written in order to portray the overall information about each criterion in a non-biased way. After these initial informational statements were written, they were reviewed by experts at The Everglades Foundation and Florida International University for content. These informational statements are outlined in Table 2.

Table 2. Informational statements for each criterion involved in the AHP analysis.

\begin{tabular}{|c|c|}
\hline Criterion & Informational Statement \\
\hline $\begin{array}{l}\text { 1. Reducing polluted } \\
\text { discharges from } \\
\text { Lake Okeechobee } \\
\text { into the St. Lucie } \\
\text { and } \\
\text { Caloosahatchee } \\
\text { rivers. }\end{array}$ & $\begin{array}{l}\text { During especially wet periods, freshwater is discharged } \\
\text { from Lake Okeechobee eastward to the St. Lucie River } \\
\text { and westward to the Caloosahatchee River. These } \\
\text { discharges are laden with excess nutrients that can lead to } \\
\text { toxic algae blooms, seagrass and oyster die-offs, and } \\
\text { negative consequences for property values and public } \\
\text { health in nearby coastal communities. Everglades } \\
\text { restoration will clean and direct water south of Lake } \\
\text { Okeechobee to the Everglades during wet periods, instead } \\
\text { of being discharged to the Caloosahatchee and St. Lucie } \\
\text { rivers, reducing the number of algal blooms in these areas }\end{array}$ \\
\hline $\begin{array}{l}\text { 2. Improving } \\
\text { seasonal flow of } \\
\text { water through } \\
\text { Everglades } \\
\text { National Park into } \\
\text { Florida Bay. }\end{array}$ & $\begin{array}{l}\text { The Greater Everglades Ecosystem is home to many } \\
\text { wildlife species that play a critical role in maintaining the } \\
\text { ecosystem and provide direct benefits to people (e.g. } \\
\text { birdwatching and recreational fishing). These species } \\
\text { include among others, the Everglades snail kite, Florida } \\
\text { panther, Florida manatee, American crocodile, spotted sea } \\
\text { trout, various species of wading birds, and the American } \\
\text { alligator. Conservation of these species will benefit from } \\
\text { the restoration of the Everglades and slow sheet flow of } \\
\text { freshwater from Lake Okeechobee through the Everglades } \\
\text { into Florida Bay. }\end{array}$ \\
\hline $\begin{array}{l}\text { 3. Reducing } \\
\text { hurricane and } \\
\text { associated storm }\end{array}$ & $\begin{array}{l}\text { Hurricanes and tropical storms are frequent natural } \\
\text { disasters in South Florida, causing flood damage } \\
\text { associated with storm surge impacts. Wetlands such as the }\end{array}$ \\
\hline
\end{tabular}




\begin{tabular}{|l|l|}
\hline $\begin{array}{l}\text { surge impact } \\
\text { provided by the } \\
\text { Everglades } \\
\text { ecosystem. }\end{array}$ & $\begin{array}{l}\text { Everglades have the ability to reduce the impacts of storm } \\
\text { surge by absorbing and storing excess flood water. } \\
\text { Mangrove swamps in the coastal Everglades are } \\
\text { especially effective at lessening the impact of storm surge. } \\
\text { Everglades restoration could potentially enhance the } \\
\text { ability of wetlands and mangrove swamps to aid in storm } \\
\text { surge mitigation. }\end{array}$ \\
\hline $\begin{array}{l}\text { 4. Increasing } \\
\text { freshwater storage } \\
\text { for residential, } \\
\text { industrial, and } \\
\text { agricultural, use. }\end{array}$ & $\begin{array}{l}\text { While the flow of freshwater is important for the } \\
\text { ecological health of the Everglades, freshwater is also an } \\
\text { important resource for agricultural use and public water } \\
\text { supply. Everglades restoration is expected to help } \\
\text { maintain and even enhance the availability of freshwater } \\
\text { for multiple uses. }\end{array}$ \\
\hline
\end{tabular}

Following each individual informational statement, respondents were asked one question about prior knowledge using a Likert scale before reading the statement. The prior knowledge question was asked to ensure that respondents reviewed the informational statement because of its importance in the AHP, as well as to compare prior knowledge about specific criteria to decision-making during the regression analysis. Prior knowledge about specific criteria could have had the potential to influence decisionmaking in the AHP section of the survey.

\subsubsection{ANALYTICAL HIERARCHY PROCESS}

The next section of the survey was the trade-off portion of the AHP analysis. Before the start of the trade-offs, an additional instructional statement using a simple trade-off example was devised to reduce the potential for inconsistency in AHP responses. Consistency in AHP response is crucial for interpreting and quantifying the responses for application in a useful way (Saaty 1978, 1981, 1990). The instructional statement example was also devised to be easily understood by a wide variety of stakeholders, as well as to explain the underlying theory of the AHP in a non-technical 
way for interested stakeholders. After an initial testing phase, the instructional statement was finalized, as seen in Figure 3.

Figure 3. Instructional statement used to explain the AHP trade-off process.

It is important that you try to make the following comparisons in a consistent fashion.

For example, you are asked to express your preferences by comparing three different fruits:

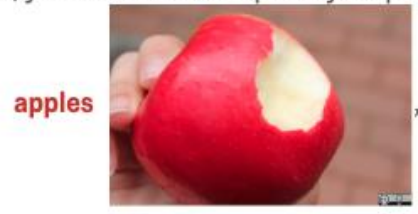

oranges
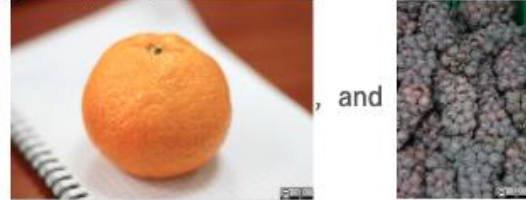

grapes.

While ranking, you express that you strongly prefer apples over oranges, but only slightly prefer grapes over oranges. Meaning that the order of your ranking would be apples first, followed by grapes second, followed by oranges third in terms of preference.

Logically, you could not prefer grapes over apples, because you prefer grapes only slightly more than oranges and you prefer apples strongly more than oranges.

If you believe that you have made choices that are not consistent, use the "previous" arrows at the bottom of each tradeoff to review your answers and change them if needed.

After the informational statement was reviewed by the respondents, AHP tradeoffs began. Each criterion was compared using pair-wise comparisons following a method originally outlined by Saaty (1990). Traditionally, AHP trade-offs between criteria are made using a numbered scale varying from 1 to 8 , with one being that the two criteria are of equal importance, and 8 being that the first criteria is absolutely more important than the second (Saaty, 1990).

While these numbered statements are effective for use in some applications of the AHP, online applications may need more careful wording. Because of importance of maintaining the consistency of responses, use of numbers of intensity to compare the criteria was replaced by more discretely-worded statements outlined in Table 3. To reduce the potential for inconsistency and confusion, intermediate values were also not included in the modified scale. While the elimination of numbered responses reduces the 
overall flexibility in potential trade-off magnitudes, it also has the advantage of making trade-offs clearer to respondents, while still maintaining the integrity and numerical meaning of the original AHP numbering system, also outlined in Table 3.

Table 3. The Saaty scale of AHP used to complete trade-offs (Saaty, 1990), and the modified scale used by this survey with the intention of improved consistency.

\begin{tabular}{|c|c|c|}
\hline Intensity of Importance & Definition (Original Scale) & Definition (Modified) \\
\hline 1 & Equal Importance & Both are equally important \\
\hline 3 & Somewhat more important & A little more important \\
\hline 5 & Much more important & Moderately more important \\
\hline 7 & Very much more important & Much more important \\
\hline 9 & Absolutely more important & Extremely more important \\
\hline $2,4,6,8$ & Intermediate Values & - \\
\hline
\end{tabular}

Each respondent made a total of six tradeoffs, eventually comparing every potential combination of two criteria. To more adequately reduce the potential for inconsistency, respondents were first asked which criteria was more important, or if they were considered equally important. If one criteria was chosen as more important than the other, the survey would ask to specify the level of importance between the two criteria based on the modified Saaty scale on a separate screen. If the criteria were chosen as equally important, the survey would continue on to the next trade-off with a different set of criteria on a separate screen.

\subsubsection{NEW ECOLOGICAL PARADIGM}

After all tradeoffs were made in the AHP, new ecological paradigm (NEP) questions were asked using the statements listed in Table 2, in the original order specified by Dunlap et al (2000). The 15 NEP questions were divided into three separate screens of five questions each to reduce the potential for respondent fatigue. Each NEP question was rated on a Likert scale of "strongly agree" to "strongly disagree" as specified in the 
updated version of the NEP by Dunlap et al. (2000). These questions and the associated Likert scale were unaltered to ensure that environmental attitude was measured as closely to the original method specified by Dunlap et al. (2000) as possible.

\subsubsection{EVERGLADES RESTORATION QUESTIONS}

Next, stakeholders were asked general questions about Everglades restoration, including opinion on Everglades restoration overall, an additional question about importance of criteria, threats facing Everglades restoration, and open response questions. The first set of general Everglades restoration questions included:

1. Cost should not be a factor in restoration of the Everglades.

2. I found it difficult to select which restoration benefit I preferred.

3. I am concerned that the government cannot manage programs effectively.

4. I should not have to pay additional fees or taxes for Everglades restoration. These questions were rated on a Likert scale of "strongly agree" to "strongly disagree." The second general Everglades restoration question was worded: "In your opinion, how important is Everglades restoration overall?" on a Likert scale of "extremely important" to "not important at all."

The next question inquired about importance of the original four criteria evaluated in the AHP, as well as two additional criteria. The question was asked to ensure that potentially relevant criteria to stakeholders that were not included in the AHP would be represented in some way in the survey. The additional criteria of Everglades restoration decision-making included:

1. Protecting recreational opportunities such as fishing, camping, and boating. 
2. Helping combat the negative effects of climate change, sea-level rise, and saltwater intrusion.

The next question enquired about the biggest threats to Everglades restoration, on a Likert scale of "none at all" to "a very large amount". The questions were included to better understand stakeholder perception of threats at the physical, governmental, and natural levels. Threats were identified using an analysis of the literature, expert consultation, and previous surveys performed in the GEE on the general public. Threats included:

1. Urban sprawl and development

2. Water pollution from agriculture

3. Water pollution from urban areas

4. Lack of funding and restoration effort by the State of Florida

5. Lack of funding and restoration effort by the Federal Government

6. Invasive species

The final set of questions in this section included two optional open-response style questions to allow for comment on greatest challenges associated with GEE restoration, as well as changes in organizational efforts associated with GEE restoration over time.

\subsubsection{DEMOGRAPHICS}

The final section of the survey collected simple demographic information, including age, gender, marital status, household size, ZIP code, education level, ethnicity, and Hispanic origin. These data collected to understand more about the general demographic factors about stakeholders. Demographics were not included in the later 
statistical analysis of motivations behind stakeholder responses due to the use of stakeholders as key informants rather than demographic representatives of the general population.

\subsubsection{STAKEHOLDER IDENTIFICATION}

Everglades restoration stakeholders were identified and contacted in a method loosely grounded in the snowball sampling approach (Noy, 2008). To begin with, Everglades and agricultural researchers at universities were identified using an online search of publicly available information. Contacted institutions included Florida International University, University of Florida, University of Miami, Florida Atlantic University, Florida Gulf Coast University, and the University of Central Florida. The survey was also sent to the Florida Coastal Everglades Long-Term Ecological Research (FCE-LTER) research group, comprised of scientists involved in every scientific facet of Everglades research. These researchers were asked to forward the survey to additional Everglades or agricultural researchers within their networks, including graduate students. Additionally, the survey was sent to all of those individuals included in the Department of Earth and Environment at Florida International University, many of which are involved in Everglades research to some degree. This was an important step, as Everglades researchers are particularly collaborative, allowing the survey to reach a greater number of researchers.

Additionally, the list of presenters from the Greater Everglades Ecosystem Restoration (GEER) Conference were contacted using publicly available information. Due to the interagency nature of GEER, presenters included stakeholders from county, state, and federal government agencies and institutions, university researchers, members 
of the business community, and agricultural researchers. GEER presenters were an especially important group to contact, due to the potential networking connections to state and federal decision-makers and policy implementers. Researchers and policymakers in this group were also asked to send the survey to others in their networks from a variety of stakeholder groups.

To contact stakeholders in the agricultural community, individual farmers with contacts at FIU, agricultural cooperatives, and UF-Institute of Food and Agricultural Sciences (IFAS) agricultural extension offices were contacted and asked to forward the link to additional farmers. Members of the business community were contacted via dissemination from mailing lists provided by multiple chambers of commerce, stretching from the Florida Keys to the northern edges of the GEE. Members of environmental advocacy groups, water utilities, and Native American tribal representatives were also contacted also using publicly available information online. All of these stakeholders were asked to forward the survey to other stakeholders within their networks. All contacted groups were sent a second reminder email to complete the survey by a given date.

Some stakeholders were contacted using personal or professional connections, and others were contacted without prior introduction. Prior introduction may have impacted the response rate of the stakeholders, due to the lack of prior interaction or connection with those stakeholders.

\subsubsection{AHP ANALYSIS}

Finally, after the survey was designed, tested, and distributed to stakeholders, responses were analyzed to answer the first research question of the thesis, pertaining to understanding which Everglades restoration criteria are most important to stakeholders. 
The Eigenvalue method developed by Saaty (1978) was utilized to calculate priority values for the criteria. Trade-off comparisons can be expressed visually using a reciprocal matrix table (Table 4). In this case, four criteria were compared to each other for a total of 6 trade-offs, and 6 reciprocal values.

Table 4. Trade-off comparisons used to calculate criteria weights in table form.

\begin{tabular}{|c|c|c|c|c|}
\hline Criteria & $\mathbf{1}$ & $\mathbf{2}$ & $\mathbf{3}$ & $\mathbf{4}$ \\
\hline $\mathbf{1}$ & 1 & Reciprocal & Reciprocal & Reciprocal \\
\hline $\mathbf{2}$ & $\begin{array}{c}\text { Comparison 1 } \\
\text { (Trade-off between } \\
\text { criterion 1 and 2) }\end{array}$ & 1 & Reciprocal & Reciprocal \\
\hline $\mathbf{3}$ & Comparison 2 & Comparison 4 & 1 & Reciprocal \\
\hline $\mathbf{4}$ & Comparison 3 & Comparison 5 & Comparison 6 & 1 \\
\hline
\end{tabular}

The matrix can also be expressed in a theoretical reciprocal matrix where the relative weight of an attribute is included in the matrix as $a_{i j}$ and the reciprocal to that weight is represented as $1 / a_{i j}$ on a diagonal:

$$
A=a_{i j}=\begin{array}{cccc}
w_{1} / w_{1} & w_{1} / w_{2} & \ldots & w_{1} / w_{n} \\
w_{2} / w_{1} & w_{2} / w_{2} & \ldots & w_{2} / w_{n} \\
\vdots & \vdots & \ldots & \vdots \\
w_{n} / w_{1} & w_{n} / w_{2} & \ldots & w_{n} / w_{n}
\end{array}
$$

As seen in matrix A, each factor with respect to the others is shown as ratios on rows.

When $i=j, a_{i j}=1$. When the transpose of the vector of weights $w$ is multiplied by matrix A, a vector is represented by $\lambda \max w$, where

$$
A w=\lambda \max
$$

where,

$$
w=\left(w_{1}, w_{2}, \ldots w_{n}\right)^{T}
$$

And,

$$
\left(A-\lambda_{\max } I\right) w=0
$$


Where $\lambda_{\max }$ is the largest Eigen value of matrix $\mathrm{A}$ and $w$ is the transpose of the vector weights. $I$ refers to the identity matrix. The $\lambda_{\max }$ is equal to or greater than $n$ or the number of rows or columns in the matrix A (Saaty, 1977).

Because of the potential for inconsistency in responses, especially when applying the AHP in an online survey format, consistency of responses had to be calculated. A consistency index for each individual respondent was calculated using the following formula:

$$
\frac{\left(\lambda_{\max }-n\right)}{(n-1)}
$$

Where $\lambda_{\max }$ is the largest Eigen value of matrix $\mathrm{A}$ and $n$ is the number of criteria being analyzed. The consistency index was then divided by the consistency index of the specific matrix used in the analysis. The calculation resulted in a consistency ratio, interpreted such that ratios greater than 0.1 were considered inconsistent (Saaty \& Vargas, 2012). Each response was evaluated for consistency to only include those responses that were considered consistent at the end of the analysis.

Using the above theoretical guidance, AHP calculations were completed using the statistical analysis program STATA. At the end of the AHP analysis process, weights were calculated for the total sample, allowing for understanding of which restoration criteria and alternatives are most important.

\subsection{RESEARCH QUESTION 2: WHAT ARE THE PREFERENCE DIFFERENCES BETWEEN STAKEHOLDERS?}

To answer the second research question, the AHP analysis was replicated on individual stakeholder groups to understand priority weights of each group for 
comparison. Because of smaller sample sizes from certain stakeholder groups, stakeholders were grouped together according to major interest. These groups include: researcher (comprised of university professors and graduate students), government (including county, state, and federal government employees and water utilities), agriculture researcher (including those who indicated both agricultural and university researcher involvement), environmental organizations, business (including recreational interests, business community, and real estate), Native American tribal interests, natural resources, and other (including "other", and prefer not to say). The consolidation resulted in a total of seven stakeholder groups. Similarities and differences among the preferences of these groups were compared using each individual stakeholder group's comparative weights at the end of the AHP weight calculation.

Additionally, regression analysis was used to understand the degree to which the stakeholder groups differed in terms of preference. The stakeholder group that expressed the highest weight, or WeightHighest Stakeholder, in terms or preference was utilized as the dependent variable, while the dependent variables included the 6 other stakeholder groups, expressed in the equation below:

\section{Weight Highest Stakeholder $=$ B0 + B1StakeholderGroup1 + B2StakeholderGroup $2+$ B3StakeholderGroup3 + B4StakeholderGroup4 + B5StakeholderGroup5 + B6 StakeholderGroup6 $+\varepsilon$}

With $\varepsilon$ being the error term, or any random variable that could affect the differences between weights. The regression process would reveal those stakeholder groups that expressed significantly lower weights than the stakeholder group that expressed the highest weight. 


\subsection{RESEARCH QUESTION 3: WHICH FACTORS INFLUENCE STAKEHOLDER}

\section{CHOICES?}

The third part of the analysis involved attempting to understand which factors collected by the survey may be able to explain motivations behind stakeholder decisionmaking. A simple regression analysis was performed to better understand the potential motivations behind AHP decisions. The weights expressed by stakeholders on each individual criteria was regressed with other collected information including stakeholder group, NEP scale score, prior knowledge, education level, Everglades restoration attitudinal responses, and age.

\subsubsection{REGRESSION ANALYSIS}

The simple regression analysis was performed using STATA software. Regression was performed with individual priority weights as a dependent variable, and additional information collected by the survey as the independent variables.

Combinations of variables were tested to better understand those that had some significance to the individual priority weights. The regression analysis method can be theoretically expressed with the following equation:

$$
\text { WeightCriteria }=B_{0}+B \text { Stakeholder }+B_{2} N E P+B 3 \text { Education Level }+B 4 \text { Attitudes }+\varepsilon
$$

Where Weightcriteria is the weight of each individual criteria as the independent function, and $\mathrm{B}_{0}$ is the intercept of the regression line. Each dependent variable involved in the analysis is represented by $\mathrm{B}_{1}$ Stakeholder, or the stakeholder group associated with each respondent, $\mathrm{B}_{2} \mathrm{NEP}$, or the overall environmental attitude score of each individual respondent, $\mathrm{B}_{3}$ Education Level, or the highest achieved level of education on a scale of less than high school to professional degree, and B4Attitudes, or responses to the 
Everglades restoration attitudinal questions. $\varepsilon$ is an error term, due to the fact that not all factors that influence criteria weight could possibly be recorded in the present thesis.

Additionally, a seemingly unrelated regression with small sample size adjustment was utilized to understand both the statistical differences between the criteria weights, stakeholder group, and demographic variables.

\subsection{RESEARCH QUESTION 4: WHAT ARE THE ENVIRONMENTAL ATTITUDES OF STAKEHOLDERS?}

The fourth part of the analysis involved quantifying individual stakeholder responses to the New Ecological Paradigm questions to assess environmental attitude. Following the methods and statements originated by Dunlap et al. $(1978,2000)$ shown in Table 2, stakeholders were asked a series of 15 environmental attitude questions on a Likert scale of "Strongly agree" to "strongly disagree", with five possible response options. In order to calculate the environmental attitude score, each response was translated to a number between one and five, then totaled. Due to the alternating ecocentric and anthropocentric statements in the NEP, anthropocentric responses were transposed. Strong agreement with anthropocentric statements translated to a lower score in comparison to ecocentric statements. Higher NEP score equated to higher degree of agreement with ecocentric statements.

Following this reasoning, the highest possible and most ecocentric score on the NEP scale is a 75, while the lowest possible and most anthropocentric score on the NEP scale is a 15. The total scores of each respondent were included in the regression analysis in the third research question of the present thesis. Additionally, respondents were broken up into three separate groups based on NEP score. Those with a score less than 45 (the 
midpoint score representing NEP neutrality) were considered more anthropocentric, while those with a score higher than 45 were considered more ecocentric. The NEP score metric is helpful when attempting to understand the ideological differences between stakeholders.

\subsection{RESEARCH QUESTION 5: HOW CAN PREFERENCE STRUCTURES OF}

\section{DIFFERENT STAKEHOLDERS INFLUENCE SELECTION OF ALTERNATIVES?}

The final part of the analysis applies the calculated criteria weights found in the AHP analysis to actual potential GEE restoration projects. While CERP contains more than 60 individual projects with several outcomes, installment of a reservoir south of the Everglades Agricultural Area (EAA) may have the potential to reduce many of the issues facing restoration efforts, including reducing polluted discharges from Lake Okeechobee, increasing seasonal flow of water through the GEE, and increasing water storage for environmental use. However, the storage size of the reservoir has not been determined. Potential alternatives include either a $0.24,0.5,1,1.5$, or 2-million-acre-foot reservoir.

To compare the potential outcomes of different restoration scenarios, the physical outcomes of each restoration criteria under different potential alternatives had to be determined. Outcomes were found using ecological and hydrological models produced by the science team at The Everglades Foundation. These physical values include different water storage amounts, ecological changes to wildlife populations in Everglades National Park, and reduced polluted discharges from Lake Okeechobee into the northern estuaries. To complete the AHP, criteria weights and physical values for each restoration alternative were compared using multi-attribute value theory (MAVT). 


\subsubsection{MULTI-ATTRIBUTE VALUE THEORY}

Multi-attribute value theory is a tool used in multi-criteria analyses to combine both physical outcomes of different choice alternatives, and the preferential outcomes of methods such as the AHP. The MAVT process allows for easier ranking in the final step of the AHP, while also reflecting stakeholders' value judgements through alternative rankings (Fishburn 1967, Keeney \& Raiffa, 1993). Following the work of Hostmann et al., (2005), the MAVT process was completed using the following value function:

$$
V_{i}\left(x_{i, j}\right)=w_{1} * v_{i 1}\left(x_{i 1}\right)+w_{2} * v_{i 2}\left(x_{i 2}\right)+\cdots+w_{n} * v_{i n}\left(x_{i n}\right)
$$

for each $i$,

Where $V i$ is the unitless aggregate index for restoration alternative $i, x_{i l}$ is the physical value of attribute 1 under restoration alternative $i, W_{l}$ is the stakeholder-generated weight of the attribute 1 , and $V_{i l}$ is the normalized value of attribute 1 under alternative 1 . Additionally, $i$ is the normalized value of attribute $l$ under alternative $i, i=1,2, \ldots n$ restoration alternatives and $j=1,2, \ldots n$ attributes. The resulting outcome of the analysis is a number between 0-1, allowing for each restoration alternative to be compared on a weighted scale. All of the values used in the equation were normalized before input into the equation, meaning that use of the $V_{i l}$ was not needed in this analysis.

With multiple attributes embedded into a single scale, the value function allows comparing alternatives simultaneously based on ecological, economic, and social dimensions for restoration (Mavrommati et al., 2016). Additionally, the above function assumes that multiple restoration attributes are independent of each other, meaning that there are no interactions among preferences for the levels of different attributes, known as mutual preference independence (Mavrommati et al., 2016). Simply, the concept of 
mutual preference independence states that alternatives involved in decision-making are weighed evenly in terms of preference and are not impacted by one another. Mutual preference independence allowed for substitution of weak performance of one attribute for a strong performance in another attribute. Completion of the MAVT signaled the concluding step to the AHP analysis, which involves using stakeholder preference of GEE restoration alternatives to decide which real-world restoration scenarios would provide the most benefit to stakeholders.

The physical values used in the MAVT analysis are already normalized in to percentages with information provided by scientists at The Everglades Foundation. The first data set used in the MAVT analysis included percentage reduction in discharges from Lake Okeechobee into the northern estuaries as a result of the five different storage amounts in the EAA, representing the physical value of the discharges criteria. These values are listed in Table 5.

Table 5. Reduction in polluted discharges from Lake Okeechobee as a result of 5 different restoration alternatives.

\begin{tabular}{|c|c|c|c|c|c|}
\hline $\begin{array}{c}\text { Reservoir Size } \\
\text { (in million acre- } \\
\text { feet) }\end{array}$ & $\mathbf{0 . 2 4}$ & $\mathbf{0 . 5}$ & $\mathbf{1}$ & $\mathbf{1 . 5}$ & $\mathbf{2}$ \\
\hline $\begin{array}{c}\text { \% Reduction in } \\
\text { Polluted } \\
\text { Discharges }\end{array}$ & $57.074 \%$ & $59.953 \%$ & $62.198 \%$ & $63.3007 \%$ & $63.768 \%$ \\
\hline
\end{tabular}

The second data set used in the MAVT analysis included an average percentage increase in select indicator species populations in Everglades National Park, including wading birds, alligators, snail kites, and seatrout. The resulting physical value represented the flow criteria, listed on Table 6. Modeling of the third and fourth datasets representing 
the water storage and storm surge protection is currently underway. The MAVT was completed using two of the four criteria, with potential to add the additional two criteria as they are made available.

Table 6. Physical increase in indicator species populations as a result of 5 different restoration alternatives based on average of four different species.

\begin{tabular}{|c|c|c|c|c|c|}
\hline \multicolumn{6}{|c|}{ Reservoir Size (in million acre-feet) } \\
\hline $\begin{array}{c}\text { Indicator } \\
\text { Species }\end{array}$ & $\mathbf{0 . 2 4}$ & $\mathbf{0 . 5}$ & $\mathbf{1}$ & $\mathbf{1 . 5}$ & $\mathbf{2}$ \\
\hline $\begin{array}{c}\text { Wading } \\
\text { Birds }\end{array}$ & $2.48 \%$ & $2.96 \%$ & $3.41 \%$ & $3.53 \%$ & $3.53 \%$ \\
\hline Alligators & $6.95 \%$ & $9.07 \%$ & $10.01 \%$ & $10.00 \%$ & $8.57 \%$ \\
\hline Snail Kite & $18.26 \%$ & $23.88 \%$ & $27.53 \%$ & $27.60 \%$ & $26.34 \%$ \\
\hline Seatrout & $25.15 \%$ & $26.37 \%$ & $27.39 \%$ & $28.62 \%$ & $28.62 \%$ \\
\hline AVERAGE & $\mathbf{1 3 . 2 1 \%}$ & $\mathbf{1 5 . 5 6 \%}$ & $\mathbf{1 7 . 0 8 \%}$ & $\mathbf{1 7 . 4 3 \%}$ & $\mathbf{1 6 . 7 6 \%}$ \\
\hline
\end{tabular}




\section{CHAPTER 4. DISCUSSION}

The chapter presents and discusses the results of the analysis relating to each individual research question listed in the methodology section. These results include a ranking of the most important outcomes of Everglades restoration to stakeholders, differences in preferences between stakeholders, potential motivations of stakeholder decision-making, the environmental attitudes of stakeholders, and applications of the outcomes of the study to real restoration scenarios.

\subsection{WHAT ARE THE MOST IMPORTANT OUTCOMES OF EVERGLADES RESTORATION TO STAKEHOLDERS?}

Due to the importance of capturing a wide variety of viewpoints and perspectives, the online survey utilized in the present research was sent to over 500 known individuals, some of which sent the survey to additional stakeholders or email lists. Of the stakeholders contacted, 106 individuals completed at least the prior knowledge and AHP trade-off sections of the survey, resulting in 21.2 percent response rate. Stakeholder groups represented in the final sample included university researchers at the professorial and graduate level $(n=45)$, representatives from the county, state, and federal government $(n=28)$, an agricultural representative $(n=1)$, agricultural researchers $(n=$ 4), environmental organization representatives $(n=8)$, business community representatives $(n=15)$, natural resource representatives $(n=3)$, and others who did not identify with any group on the stakeholder list $(n=2)$. Some responses to the Analytical Hierarchy process section of the survey were not considered consistent enough to include in the final analysis. Consistent stakeholder group responses are outlined in Table 7. 
Certain stakeholder groups that proved especially difficult to contact included Native American tribal representatives and agricultural representatives.

Table 7. Consistent responses after Analytical Hierarchy Process

\begin{tabular}{|c|c|c|}
\hline Stakeholder Group & Responses & Consistent Responses \\
\hline University Researchers & 45 & 39 \\
\hline $\begin{array}{c}\text { Government (County, state, } \\
\text { federal) }\end{array}$ & 28 & 25 \\
\hline Agriculture & 1 & 0 \\
\hline Agriculture Researchers & 4 & 4 \\
\hline Environmental Organizations & 8 & 6 \\
\hline Business Community & 15 & 14 \\
\hline Natural Resources & 3 & 3 \\
\hline Other & 2 & $\mathbf{9 3}$ \\
\hline Total & $\mathbf{1 0 6}$ & \\
\hline
\end{tabular}

\subsubsection{OVERALL DECISIONS}

The overall preference weights of the Everglades restoration criteria included in the AHP trade-offs are expressed in Table 8. According to all 106 surveyed responses combined, improving seasonal flow of water through ENP into Florida Bay was listed as the most important criterion (0.3489) when proceeding with Everglades restoration scenarios (referred to as "Flow"). Flow was followed in declining order by reducing polluted discharges from Lake Okeechobee (Discharges, 0.2947), reducing hurricane and associated storm surge impact provided by the Everglades ecosystem (Hurricanes, 0.1792), and increasing freshwater storage for residential, industrial, and agricultural use (Water, 0.1772), which was weighted the lowest in terms of preferences for Everglades restoration criteria. The result may have been due to the small amount of agricultural and business community responses captured in the present survey, in comparison to Everglades researchers. 
A series of simple t-tests revealed that preference for flow was significantly higher than each of the other criteria. The t-tests also revealed that preference for discharges was significantly higher than preference for both hurricanes and water. Additionally, the preferences for hurricanes and water were not significantly different.

Table 8. Overall AHP Preference Weights

\begin{tabular}{|c|c|c|c|c|}
\hline $\begin{array}{c}\text { Criteria } \\
\text { Name }\end{array}$ & $\begin{array}{c}\text { Reducing polluted } \\
\text { discharges from Lake } \\
\text { Okeechobee into the St. } \\
\text { Lucie and } \\
\text { Caloosahatchee rivers. }\end{array}$ & $\begin{array}{c}\text { Reducing hurricane } \\
\text { and associated storm } \\
\text { surge impact provided } \\
\text { by the Everglades } \\
\text { ecosystem. }\end{array}$ & $\begin{array}{c}\text { Improving seasonal } \\
\text { flow of water through } \\
\text { Everglades National } \\
\text { Park into Florida Bay. }\end{array}$ & $\begin{array}{c}\text { Increasing } \\
\text { freshwater storage } \\
\text { for residential, } \\
\text { industrial, and } \\
\text { agricultural, use. }\end{array}$ \\
\hline $\begin{array}{c}\text { Shorthand } \\
\text { Criteria } \\
\text { Name }\end{array}$ & Discharges & Hurricanes & Flow & Water \\
\hline $\begin{array}{c}\text { Overall } \\
\text { Weights }\end{array}$ & $\mathbf{0 . 2 9 4 7}$ & $\mathbf{0 . 1 7 9 2}$ & $\mathbf{0 . 3 4 8 9}$ & $\mathbf{0 . 1 7 7 2}$ \\
\hline
\end{tabular}

\subsubsection{STAKEHOLDER GROUP DECISIONS}

When the AHP analysis was performed within individual stakeholder groups, results differed from the overall results dramatically as expressed in Table 9. Researchers, government employees, environmental organization employees, and natural resource interests had the highest preference for flow, followed by discharges, hurricanes, and water. Business community representatives had the highest preference for flow, followed by discharges, water, and hurricanes. The agricultural researchers had highest preference for water storage, with equal preference for discharges, hurricanes, and flow. Inconsistent responses were not included in the analysis

The stakeholder group with the highest priority for discharges out of all of the groups was the natural resource group, while the group with lowest priority was the agriculture researcher group. The stakeholder group with the highest priority for restoring 
the GEE to improve resilience from hurricanes was the agricultural researcher group, closely followed by environmental organizations, while the groups with the lowest priority were government and researchers. The stakeholder group with the highest priority for improving flow through the GEE was government, while the agriculture research representative expressed the lowest priority. The stakeholder group with the highest priority for increasing water storage was the agriculture researcher group, while the environmental organization representatives expressed the lowest priority.

Table 9. AHP Preference Weights for Individual Stakeholder Groups

\begin{tabular}{|c|c|c|c|c|}
\hline $\begin{array}{c}\text { Stakeholder } \\
\text { Group }\end{array}$ & Discharges & Hurricanes & Flow & Water \\
\hline $\begin{array}{c}\text { Researcher } \\
(\mathbf{n = 4 5})\end{array}$ & .301 & .172 & .346 & .181 \\
\hline $\begin{array}{c}\text { Government } \\
(\mathbf{n}=\mathbf{2 8})\end{array}$ & .282 & .167 & $\mathbf{. 4 0 6}$ & .145 \\
\hline $\begin{array}{c}\text { Agricultural } \\
\text { Researcher } \\
(\mathbf{n}=\mathbf{4})\end{array}$ & .229 & $\mathbf{. 2 2 9}$ & .229 &. $\mathbf{3 1 3}$ \\
\hline $\begin{array}{c}\text { Environmental } \\
\text { Organization } \\
(\mathbf{n}=\mathbf{8})\end{array}$ & .286 & .205 & .373 & .136 \\
\hline $\begin{array}{c}\text { Business } \\
(\mathbf{n}=\mathbf{1 5})\end{array}$ & .302 & .183 & .303 & .212 \\
\hline $\begin{array}{c}\text { Natural } \\
\text { Resources } \\
(\mathbf{n}=\mathbf{3})\end{array}$ & $\mathbf{. 3 2 3}$ & .194 & .340 & .144 \\
\hline $\begin{array}{c}\text { Overall } \\
\text { Weight }\end{array}$ & $\mathbf{0 . 2 9 4 7}$ & $\mathbf{. 1 7 9 2}$ & $\mathbf{. 3 4 8 9}$ & $\mathbf{. 1 7 7 2}$ \\
\hline
\end{tabular}

Bold: Stakeholder group with the highest weight.

Due to the small sample size of some stakeholder groups, analysis to find the significance of weights when compared to other stakeholders was not possible. The finapotential for successful statistical analysis could be further improved with larger sample sizes from certain groups, such as agriculture, environmental organizations, and 
business. The analysis could also be significantly enriched by further involvement from Native American tribal representatives.

Researchers represented the largest stakeholder group in the sample, with highest preferences for restored Flow. While researchers may have the most intimate understanding of a variety of GEE functions and outcomes of restoration scenarios, input is often overshadowed by special interests or those with political power. The academic community sampled in the present study is comprised of a multi-disciplinary group of experts with a variety of perspectives and varied geographical coverage of the GEE. As called for by Scarlett (2013), decision-making processes utilized in the present study includes input from the scientific community, among other represented stakeholder groups, to enrich input and expertise on Everglades restoration from a variety of sources. The present study successfully illuminated the preferences of researchers, and could be further enriched with increased participation from the other stakeholder groups to increase represented perspectives.

\subsection{WHICH FACTORS MOTIVATE STAKEHOLDER DECISIONS?}

Using simple regression analysis, demographic factors, stakeholder group identified, and environmental attitude scores were compared to the priority weights of each criterion. One individual dependent variable could not be traced to affect the priority weights of all criterion, but a few variables turned out to be significant in individual priority weight analyses. Additionally, the demographic makeup of the sample was not necessarily diverse. However, the sample of respondents was collected to represent Everglades restoration stakeholders as a whole. Demographic factors represented in the 
sample are not necessarily reflective of the general public, but Everglades restoration stakeholders as a group.

\subsubsection{DEMOGRAPHIC CHARACTERISTICS OF THE SAMPLE}

Of those respondents who answered the demographic section of the survey, 55\% identified as male, while $45 \%$ identified as female. When asked about age, approximately $8 \%$ of respondents were between the ages of 18 and $24,20 \%$ were between the ages of 25 and 34, 20\% were between the ages of 35 and $44,19 \%$ were between the ages of 45 and $54,24 \%$ were between the ages of 55 and 64 , and $10 \%$ were between the ages of 65 and 74. The youngest respondent was 22 and the oldest respondent was 71. In terms of education, approximately $48 \%$ had doctoral degrees, $16 \%$ had master's degrees, and $27 \%$ had bachelor's degrees. The variation in age may have been due to the fact that the majority of respondents, $48 \%$, were university professors or graduate students.

Respondents who attended some college or graduated from high school made up 6\% and $2 \%$ of the sample, respectively. Of those who answered the ethnicity question on the survey, approximately $78 \%$ identified as white, $4 \%$ identified as Asian, $5 \%$ identified as multiple ethnicities, $3 \%$ identified as other, and $10 \%$ preferred not to answer the question. When asked if the respondents identified as Hispanic or Latino, approximately $13 \%$ identified as Hispanic or Latino, and 75\% did not. When asked about marriage status, approximately $61 \%$ of respondents were married and $39 \%$ were not. The average household size of the sample was 2.58 individuals. The demographic trends recorded in this sample are not necessarily representative of the average demographic proportions of South Florida, but are not required to adhere to demographic quotas due to collection of information from key informants (stakeholders). 


\subsubsection{STATISCIAL ANALYSIS RESULTS}

Priority weights of each criterion were compared across the stakeholder group identified, demographic factors and NEP scores (further discussed in section 4.3 of the discussion). An additional statistical analysis called seemingly unrelated regression was also analyzed for the same variables, with overall similar results. The results of the statistical analyses are shown in Figures 4, 5, 6, 7 and 8.

The statistical analysis revealed that no one factor impacted priority weights across all four criteria. In both analyses, no known connection was found between demographic variables and preference for any criteria. However, agriculture researchers had a significantly lower preference for flow when compared to the largest stakeholder group (Researchers) and significantly higher preference for Water when compared to the largest stakeholder group.

Figure 4. Regression analysis results comparing priority weight of Discharges and other demographic, stakeholder group, and NEP scale responses.

\begin{tabular}{|c|c|c|c|c|c|c|}
\hline PriorityDischarges & Coef. & Std. Err. & $\mathrm{t}$ & $P>|t|$ & {$[95 \%$ Conf. } & Interval] \\
\hline \multicolumn{7}{|l|}{ stakeholder1_drop } \\
\hline Government & -.0192659 & .0262894 & -0.73 & 0.466 & -.0717256 & .0331939 \\
\hline Agriculture Researcher & -.0700825 & .0488696 & -1.43 & 0.156 & -.1676002 & .0274353 \\
\hline Environmental Organization & -.0197502 & .0456036 & -0.43 & 0.666 & -.1107507 & .0712504 \\
\hline Business & .0073082 & .0501336 & 0.15 & 0.885 & -.0927319 & .1073483 \\
\hline Natural Resources & .0797265 & .0757945 & 1.05 & 0.297 & -.0715192 & .2309721 \\
\hline nep & .0001709 & .0015702 & 0.11 & 0.914 & -.0029624 & .0033042 \\
\hline \multicolumn{7}{|l|}{ education } \\
\hline Some College & -.0391143 & .100517 & -0.39 & 0.698 & -.2396928 & .1614642 \\
\hline Bacelor Degree & -.0382536 & .1022922 & -0.37 & 0.710 & -.2423745 & .1658672 \\
\hline Master's Degree & -.055367 & .1103228 & -0.50 & 0.617 & -.2755127 & .1647786 \\
\hline Doctoral Degree & -.0225583 & .109143 & -0.21 & 0.837 & -.2403498 & .1952331 \\
\hline Professional Degree & -.0193669 & .1450773 & -0.13 & 0.894 & -.3088642 & .2701303 \\
\hline female & .0289932 & .0220258 & 1.32 & 0.192 & -.0149587 & .0729451 \\
\hline age & -.000144 & .0009521 & -0.15 & 0.880 & -.0020439 & .001756 \\
\hline _cons & .3160767 & .1468112 & 2.15 & 0.035 & .0231195 & .6090339 \\
\hline
\end{tabular}

(No significant variables.) 
Figure 5. Regression analysis results comparing priority weight of Flow and other demographic, stakeholder group, and NEP scale responses.

\begin{tabular}{|c|c|c|c|c|c|c|}
\hline Priorityflow & Coef. & Std. Err. & $\mathrm{t}$ & $P>|t|$ & [95\% Conf. & Interval] \\
\hline \multicolumn{7}{|l|}{ stakeholder1_drop } \\
\hline Government & .040485 & .0303932 & 1.33 & 0.187 & -.0201638 & .1011338 \\
\hline Agriculture Researcher & -.1305039 & .0564982 & -2.31 & 0.024 & -.2432443 & -.0177634 \\
\hline Environmental Organization & .0120269 & .0527224 & 0.23 & 0.820 & -.093179 & .1172328 \\
\hline Business & -.0725599 & .0579596 & -1.25 & 0.215 & -.1882164 & .0430966 \\
\hline Natural Resources & -.0244789 & .0876262 & -0.28 & 0.781 & -.1993343 & .1503765 \\
\hline nep & .0018702 & .0018153 & 1.03 & 0.307 & -.0017522 & .0054927 \\
\hline \multicolumn{7}{|l|}{ education } \\
\hline Some College & -.1195304 & .1162079 & -1.03 & 0.307 & -.3514196 & .1123588 \\
\hline Bacelor Degree & -.1387567 & .1182602 & -1.17 & 0.245 & -.3747413 & .0972278 \\
\hline Master's Degree & -.0830761 & .1275444 & -0.65 & 0.517 & -.3375869 & .1714348 \\
\hline Doctoral Degree & -.1366498 & .1261804 & -1.08 & 0.283 & -.3884389 & .1151394 \\
\hline Professional Degree & -.1860312 & .1677242 & -1.11 & 0.271 & -.5207195 & .1486572 \\
\hline female & -.0214797 & .0254641 & -0.84 & 0.402 & -.0722925 & .0293332 \\
\hline age & .0014364 & .0011007 & 1.30 & 0.196 & -.0007601 & .0036329 \\
\hline _cons & .3158733 & .1697287 & 1.86 & 0.067 & -.0228151 & .6545618 \\
\hline
\end{tabular}

(Agriculture researcher significantly lower at the 5\% confidence level.)

Figure 6. Regression analysis results comparing priority weight of Water and other demographic, stakeholder group, and NEP scale responses.

\begin{tabular}{|c|c|c|c|c|c|c|}
\hline Prioritywater & Coef. & Std. Err. & $\mathrm{t}$ & $P>|t|$ & {$[95 \%$ Conf. } & Interval] \\
\hline \multicolumn{7}{|l|}{ stakeholder1_drop } \\
\hline Government & -.0267548 & .0240756 & -1.11 & 0.270 & -.0747968 & .0212873 \\
\hline Agriculture Researcher & .1326517 & .0447543 & 2.96 & 0.004 & .043346 & .2219575 \\
\hline Environmental Organization & -.0234862 & .0417633 & -0.56 & 0.576 & -.1068236 & .0598511 \\
\hline Business & .0552998 & .0459119 & 1.20 & 0.233 & -.0363158 & .1469155 \\
\hline Natural Resources & -.0651217 & .0694119 & -0.94 & 0.351 & -.2036309 & .0733875 \\
\hline nep & -.0026972 & .001438 & -1.88 & 0.065 & -.0055667 & .0001722 \\
\hline \multicolumn{7}{|l|}{ education } \\
\hline Some College & .1248056 & .0920524 & 1.36 & 0.180 & -.0588822 & .3084933 \\
\hline Bacelor Degree & .1234625 & .0936781 & 1.32 & 0.192 & -.0634693 & .3103942 \\
\hline Master's Degree & .1196262 & .1010325 & 1.18 & 0.241 & -.081981 & .3212333 \\
\hline Doctoral Degree & .1418908 & .099952 & 1.42 & 0.160 & -.0575604 & .341342 \\
\hline Professional Degree & .0788208 & .1328603 & 0.59 & 0.555 & -.1862978 & .3439394 \\
\hline female & -.0188775 & .020171 & -0.94 & 0.353 & -.0591282 & .0213732 \\
\hline age & -.0004091 & .0008719 & -0.47 & 0.640 & -.002149 & .0013309 \\
\hline _cons & .2366067 & .1344482 & 1.76 & 0.083 & -.0316805 & .5048939 \\
\hline
\end{tabular}

(Agriculture researcher significantly higher at the 5\% level.) 
Figure 7. Regression analysis results comparing priority weight of Hurricanes and other demographic, stakeholder group, and NEP scale responses.

\begin{tabular}{|c|c|c|c|c|c|c|}
\hline PriorityHurricanes & Coef. & Std. Err. & $\mathrm{t}$ & $P>|t|$ & {$[95 \%$ Conf. } & Interval] \\
\hline \multicolumn{7}{|l|}{ stakeholder1_drop } \\
\hline Government & .0055357 & .0232948 & 0.24 & 0.813 & -.0409484 & .0520197 \\
\hline Agriculture Researcher & .0679346 & .0433029 & 1.57 & 0.121 & -.018475 & .1543442 \\
\hline Environmental Organization & .0312095 & .0404089 & 0.77 & 0.443 & -.0494252 & .1118443 \\
\hline Business & .0099518 & .0444229 & 0.22 & 0.823 & -.0786927 & .0985964 \\
\hline Natural Resources & .0098742 & .0671608 & 0.15 & 0.884 & -.1241432 & .1438915 \\
\hline nep & .0006561 & .0013914 & 0.47 & 0.639 & -.0021203 & .0034325 \\
\hline \multicolumn{7}{|l|}{ education } \\
\hline Some College & .0338391 & .0890672 & 0.38 & 0.705 & -.1438916 & .2115699 \\
\hline Bacelor Degree & .0535479 & .0906401 & 0.59 & 0.557 & -.1273217 & .2344175 \\
\hline Master's Degree & .0188169 & .097756 & 0.19 & 0.848 & -.1762521 & .2138859 \\
\hline Doctoral Degree & .0173172 & .0967106 & 0.18 & 0.858 & -.1756658 & .2103002 \\
\hline Professional Degree & .1265773 & .1285517 & 0.98 & 0.328 & -.1299436 & .3830981 \\
\hline female & .0113639 & .0195169 & 0.58 & 0.562 & -.0275814 & .0503093 \\
\hline age & -.0008834 & .0008437 & -1.05 & 0.299 & -.0025669 & .0008001 \\
\hline _cons & .1314433 & .1300881 & 1.01 & 0.316 & -.1281433 & .39103 \\
\hline
\end{tabular}

(No significant variables.) 
Figure 8. Seemingly Unrelated Regression analysis using small sample adjustment.

\begin{tabular}{|c|c|c|c|c|c|c|}
\hline & Coef. & Std. Err. & z & $P>|z|$ & [95\% Conf. & Interval] \\
\hline \multicolumn{7}{|l|}{ PriorityDischarges } \\
\hline \multicolumn{7}{|l|}{ stakeholder1_drop } \\
\hline Government & -.0192659 & .0262894 & -0.73 & 0.464 & -.0707922 & .0322605 \\
\hline Agriculture Researcher & -.0700825 & .0488696 & -1.43 & 0.152 & -.1658651 & .0257002 \\
\hline Environmental Organization & -.0197502 & .0456036 & -0.43 & 0.665 & -.1091315 & .0696312 \\
\hline Business & .0073082 & .0501336 & 0.15 & 0.884 & -.0909519 & .1055683 \\
\hline Natural Resources & .0797265 & .0757945 & 1.05 & 0.293 & -.0688281 & .228281 \\
\hline nep & .0001709 & .0015702 & 0.11 & 0.913 & -.0029067 & .0032485 \\
\hline \multicolumn{7}{|l|}{ education } \\
\hline Some College & -.0391143 & .100517 & -0.39 & 0.697 & -.236124 & .1578953 \\
\hline Bacelor Degree & -.0382536 & .1022922 & -0.37 & 0.708 & -.2387426 & .1622353 \\
\hline Master's Degree & -.055367 & .1103228 & -0.50 & 0.616 & -.2715956 & .1608616 \\
\hline Doctoral Degree & -.0225583 & .109143 & -0.21 & 0.836 & -.2364747 & .191358 \\
\hline Professional Degree & -.0193669 & .1450773 & -0.13 & 0.894 & -.3037132 & .2649794 \\
\hline female & .0289932 & .0220258 & 1.32 & 0.188 & -.0141766 & .0721631 \\
\hline age & -.000144 & .0009521 & -0.15 & 0.880 & -.0020101 & .0017221 \\
\hline _cons & .3160767 & .1468112 & 2.15 & 0.031 & .028332 & .6038214 \\
\hline \multicolumn{7}{|l|}{$\begin{array}{l}\text { PriorityHurricanes } \\
\text { stakeholder1_drop }\end{array}$} \\
\hline Government & .0055357 & .0232948 & 0.24 & 0.812 & -.0401213 & .0511926 \\
\hline Agriculture Researcher & .0679346 & .0433029 & 1.57 & 0.117 & -.0169375 & .1528067 \\
\hline Environmental Organization & .0312095 & .0404089 & 0.77 & 0.440 & -.0479905 & .1104096 \\
\hline Business & .0099518 & .0444229 & 0.22 & 0.823 & -.0771155 & .0970192 \\
\hline Natural Resources & .0098742 & .0671608 & 0.15 & 0.883 & -.1217587 & .141507 \\
\hline nep & .0006561 & .0013914 & 0.47 & 0.637 & -.0020709 & .0033831 \\
\hline \multicolumn{7}{|l|}{ education } \\
\hline Some College & .0338391 & .0890672 & 0.38 & 0.704 & -.1407293 & .2084076 \\
\hline Bacelor Degree & .0535479 & .0906401 & 0.59 & 0.555 & -.1241035 & .2311993 \\
\hline Master's Degree & .0188169 & .097756 & 0.19 & 0.847 & -.1727813 & .2104151 \\
\hline Doctoral Degree & .0173172 & .0967106 & 0.18 & 0.858 & -.172232 & .2068665 \\
\hline Professional Degree & .1265773 & .1285517 & 0.98 & 0.325 & -.1253793 & .3785339 \\
\hline female & .0113639 & .0195169 & 0.58 & 0.560 & -.0268885 & .0496163 \\
\hline age & -.0008834 & .0008437 & -1.05 & 0.295 & -.0025369 & .0007702 \\
\hline _cons & .1314433 & .1300881 & 1.01 & 0.312 & -.1235246 & .3864113 \\
\hline \multicolumn{7}{|l|}{ Priorityflow } \\
\hline Government & .040485 & .0303932 & 1.33 & 0.183 & -.0190847 & .1000546 \\
\hline Agriculture Researcher & -.1305039 & .0564982 & -2.31 & 0.021 & -.2412384 & -.0197693 \\
\hline Environmental Organization & .0120269 & .0527224 & 0.23 & 0.820 & -.0913071 & .1153608 \\
\hline Business & -.0725599 & .0579596 & -1.25 & 0.211 & -.1861586 & .0410388 \\
\hline Natural Resources & -.0244789 & .0876262 & -0.28 & 0.780 & -.1962231 & .1472653 \\
\hline nep & .0018702 & .0018153 & 1.03 & 0.303 & -.0016878 & .0054282 \\
\hline \multicolumn{7}{|l|}{ education } \\
\hline Some College & -.1195304 & .1162079 & -1.03 & 0.304 & -.3472937 & .1082328 \\
\hline Bacelor Degree & -.1387567 & .1182602 & -1.17 & 0.241 & -.3705424 & .093029 \\
\hline Master's Degree & -.0830761 & .1275444 & -0.65 & 0.515 & -.3330584 & .1669063 \\
\hline Doctoral Degree & -.1366498 & .1261804 & -1.08 & 0.279 & -.3839589 & .1106593 \\
\hline Professional Degree & -.1860312 & .1677242 & -1.11 & 0.267 & -.5147645 & .1427021 \\
\hline female & -.0214797 & .0254641 & -0.84 & 0.399 & -.0713884 & .0284291 \\
\hline age & .0014364 & .0011007 & 1.30 & 0.192 & -.000721 & .0035938 \\
\hline _cons & .3158733 & .1697287 & 1.86 & 0.063 & -.0167889 & .6485356 \\
\hline
\end{tabular}




\begin{tabular}{|c|c|c|c|c|c|c|}
\hline \multicolumn{7}{|l|}{$\begin{array}{l}\text { PriorityWater } \\
\qquad \text { stakeholder1_drop }\end{array}$} \\
\hline Government & -.0267548 & .0240756 & -1.11 & 0.266 & -.073942 & .0204325 \\
\hline Agriculture Researcher & .1326517 & .0447543 & 2.96 & 0.003 & .044935 & .2203685 \\
\hline Environmental Organization & -.0234862 & .0417633 & -0.56 & 0.574 & -.1053408 & .0583683 \\
\hline Business & .0552998 & .0459119 & 1.20 & 0.228 & -.0346857 & .1452854 \\
\hline Natural Resources & -.0651217 & .0694119 & -0.94 & 0.348 & -.2011665 & .070923 \\
\hline nep & -.0026972 & .001438 & -1.88 & 0.061 & -.0055157 & .0001212 \\
\hline \multicolumn{7}{|l|}{ education } \\
\hline Some College & .1248056 & .0920524 & 1.36 & 0.175 & -.0556138 & .305225 \\
\hline Bacelor Degree & .1234625 & .0936781 & 1.32 & 0.188 & -.0601433 & .3070682 \\
\hline Master's Degree & .1196262 & .1010325 & 1.18 & 0.236 & -.0783938 & .3176461 \\
\hline Doctoral Degree & .1418908 & .099952 & 1.42 & 0.156 & -.0540116 & .3377932 \\
\hline Professional Degree & .0788208 & .1328603 & 0.59 & 0.553 & -.1815806 & .3392222 \\
\hline female & -.0188775 & .020171 & -0.94 & 0.349 & -.058412 & .020657 \\
\hline age & -.0004091 & .0008719 & -0.47 & 0.639 & -.002118 & .0012999 \\
\hline _cons & .2366067 & .1344482 & 1.76 & 0.078 & -.0269069 & .5001203 \\
\hline
\end{tabular}

Note: Due to the nature of completing the seemingly unrelated regression, all four priority weights were not comparable at the same time. The fourth priority criteria (Water) was analyzed in a separate analysis that eliminated Hurricanes. This is because the fourth equation would be a perfectly linear combination of the other three equations.

Figure 8 reflects the same outcomes as the previous figures, using an additional strategy for statistical analysis called Seemingly Unrelated Regression. The Seemingly Unrelated Regression method was used because the error terms in the regression analysis between the preference structures may be correlated. The method yielded the same results, namely that agricultural researchers have a significantly higher preference for water provision and a significantly lower preference for flow to the GEE.

\subsection{WHAT ARE THE ENVIRONMENTAL ATTITUDES OF EVERGLADES RESTORATION STAKEHOLDERS?}

The results of the NEP scale portion of the online survey revealed that only a small number of respondents $(\mathrm{n}=2)$ identified as neutral in environmental attitude or anthropocentric in environmental attitude. The remaining respondents with completed NEP scale responses identified as some level of ecocentric $(n=100)$. The result is consistent with recent studies such as Dunlap et al. (2000) and Dunlap (2008). A small 
portion of the respondents finished the AHP trade-off section, but did not complete the NEP scale section of the survey (4). The section is also divided into examining the overall NEP scores and average NEP scores for each stakeholder group.

\subsubsection{NEP OVERALL RESPONDENTS}

Overall, NEP scores were concentrated towards more ecocentric responses. The NEP scale stretches from the lowest possible score of 15 , to the highest possible score of 75. The majority of the sample (76 individuals) scored between 60 and 70, expressing environmental attitude ranging from mildly to strongly ecocentric. Another portion of the sample (12 individuals) scored between 50 and 59, expressing slightly ecocentric attitudes. A smaller portion (12 individuals) scored between 70 and 75 , expressing extremely ecocentric views. Two individuals expressed either neutral or slightly anthropocentric views. These trends are expressed in Figure 9.

Figure 9. Distribution of NEP scores in the sample of stakeholders.

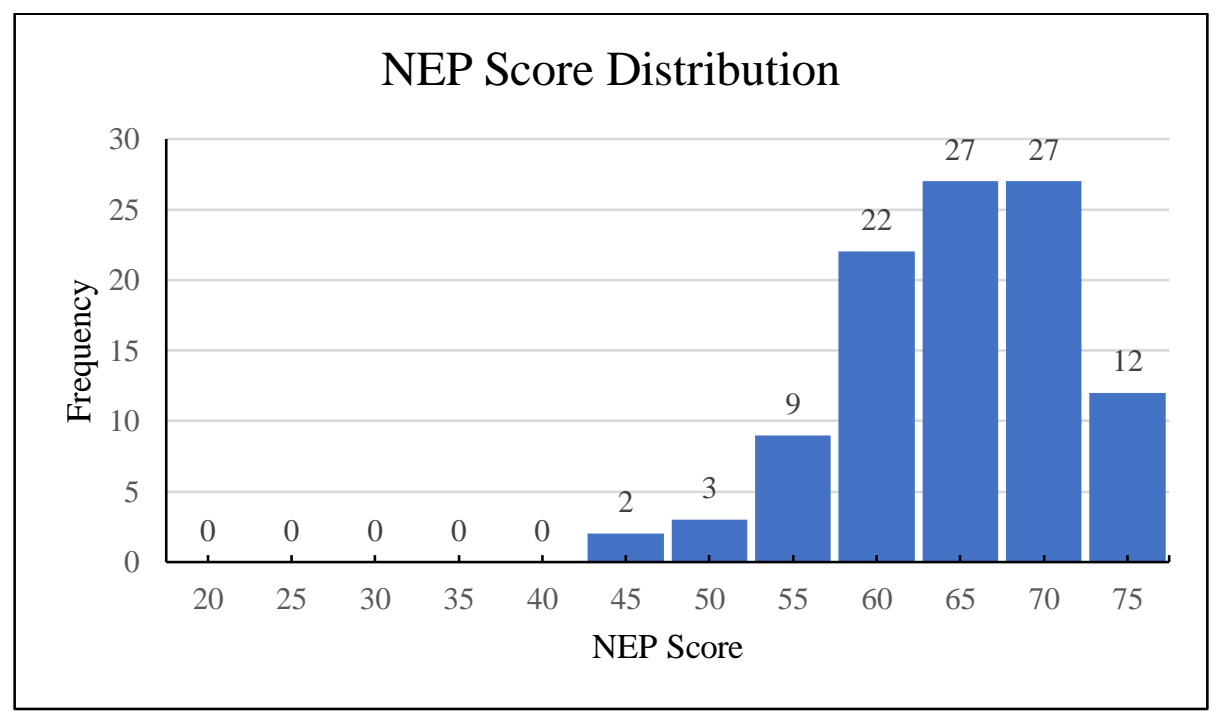


Collection of additional responses from agricultural representatives, the business community, and Native American tribal representatives have the potential to integrate additional ideologies into the NEP results to enrich the distribution of scores. The NEP scores of each stakeholder group were also calculated and compared in the following section.

\subsubsection{NEP STAKEHOLDER GROUPS}

Average NEP scores differed in most of the stakeholder groups, but varied from the lowest score of 55 (Agriculture) to the highest score of 68 (Environmental Organization). These averages are displayed in Table 10. Though the average scores were different, the range was only 13 points on the NEP scale, signaling that the surveyed stakeholder groups may hold similar environmental attitudes. Ecological attitude is important to know for communication with stakeholder groups, as well as messaging for stakeholder groups for policy-making, decision-making, and communication purposes on the part of decision-makers.

Table 10. Average NEP scores of each stakeholder group.

\begin{tabular}{|c|c|}
\hline Stakeholder Group & Average NEP Score \\
\hline $\begin{array}{c}\text { Agriculture } \\
(\mathrm{n}=1)\end{array}$ & 55 \\
\hline $\begin{array}{c}\text { Agriculture Researcher } \\
(\mathrm{n}=4)\end{array}$ & 59 \\
\hline $\begin{array}{c}\text { Business } \\
(\mathrm{n}=15)\end{array}$ & 62 \\
\hline $\begin{array}{c}\text { Environmental Organization } \\
(\mathrm{n}=8)\end{array}$ & 68 \\
\hline $\begin{array}{c}\text { Government } \\
(\mathrm{n}=28)\end{array}$ & 63 \\
\hline $\begin{array}{c}\text { Natural Resources } \\
(\mathrm{n}=3)\end{array}$ & 64 \\
\hline $\begin{array}{c}\text { Researcher } \\
(\mathrm{n}=45)\end{array}$ & 62 \\
\hline
\end{tabular}


The agriculture group and agricultural researcher group were the only two groups to score below 60 on the NEP scale, still displaying a slightly ecocentric attitude. These groups likely maintain a slightly more anthropocentric viewpoint than the rest of the sample potentially due to a utilitarian understanding of the environment as a provider of resources for agricultural practices. The results of the NEP scale questions would be enriched with further sampling from additional agricultural representatives, especially considering that only one purely agricultural representative was sampled.

The business group and researcher groups both displayed an average score of 62, with government narrowly reflecting a higher score at 63 . The higher score may be due to the higher proportion of researchers included in the survey, displaying a sample with more diverse environmental attitudes. The result was surprising due to the potential ideological differences between the three groups, especially in regards to the researcher group. The scores of the environmental organization group and the natural resources group are slightly higher than the rest of the sample.

While most of the individual stakeholders expressed some form of an ecocentric environmental attitude, some other factor may be able to explain the ideological differences between the stakeholders. Additional analyzation of the NEP results, including a factor analysis, may be able to provide some insight into the main differences between responses to the NEP questions. Additional responses to the NEP questions have the potential to display an overall more holistic understanding of the environmental attitudes of a wider variety of respondents. Groups that may be able to provide an 
especially interesting perspective include Agricultural representatives and researchers, Native American tribal representatives, and the business community at large.

\subsection{HOW CAN PREFERENCE STRUCTURES OF DIFFERENT STAKEHOLDERS INFLUENCE SELECTION OF ALTERNATIVES?}

Finally, the MAVT was performed to understand how the preferences defined by the AHP analysis have the potential to influence decision-making in a realistic way. As stated in the methodology section of the present thesis, the MAVT was limited to two physical values of restoration alternatives representing flow and discharges. In the coming months, developments in ecological modeling will allow for application of the third and fourth physical values representing water storage and hurricane damage reduction. Thankfully, the two currently available physical outcomes of the restoration scenarios coincide with the two most preferred outcomes of the overall AHP analysis. Investigation of alternative EAA reservoirs is just one application of the results of the survey, the same process can be replicated on any number of restoration alternatives with the same measurable outcomes.

\subsubsection{MULTI-ATTRIBUTE VALUE THEORY OUTCOMES}

Each restoration alternative, including EAA reservoirs with storage amounts ranging from 0.25 to 2 million acre-feet, were weighed based on both the preferences of stakeholders and the physical changes in discharges and flow as a result of different storage amounts (outlined in Tables 5 and 6). Generally, larger reservoir sizes decreased the overall amount of polluted discharges flowing from Lake Okeechobee into the St. Lucie and Caloosahatchee estuary systems (as seen in Table 5). However, larger reservoir size was not always associated with increased populations of indicator species in 
Everglades National Park (ENP), indicating that some levels of increased seasonal water flow through ENP actually may have negative effects on wildlife populations (as seen in Table 6). Table 11 outlines the normalized values of each of the criteria, with the Hurricane criteria neutralized to the same impact with each individual restoration alternatives.

Table 11. Normalized values of physical impacts of each restoration alternative.

\begin{tabular}{|c|c|c|c|c|}
\hline $\begin{array}{c}\text { Reservoir Size } \\
\text { (million acre- } \\
\text { feet) }\end{array}$ & $\begin{array}{c}\text { \% Reduced } \\
\text { Discharges } \\
\text { from Lake } \\
\text { Okeechobee }\end{array}$ & $\begin{array}{c}\text { \% Increased } \\
\text { Population of } \\
\text { Indicator } \\
\text { Species in ENP }\end{array}$ & $\begin{array}{c}\text { \% Increase in } \\
\text { Water Storage }\end{array}$ & $\begin{array}{c}\% \text { Increase in } \\
\text { Storm Surge } \\
\text { and Hurricane } \\
\text { Protection }\end{array}$ \\
\hline 0.24 & $57 \%$ & $13 \%$ & $12 \%$ & $100 \%$ \\
\hline 0.5 & $60 \%$ & $16 \%$ & $25 \%$ & $100 \%$ \\
\hline 1 & $62 \%$ & $17 \%$ & $50 \%$ & $100 \%$ \\
\hline 1.5 & $64 \%$ & $17 \%$ & $75 \%$ & $100 \%$ \\
\hline 2 & & $100 \%$ & $100 \%$ \\
\hline
\end{tabular}

Calculations using the MAVT formula reveal that the largest reservoir size of 2 million acre-feet is weighed the highest out of all other alternatives. However, the weight of the $1.5 \mathrm{M}$ acre-foot alternative is only slightly less than the highest weighed alternative. The $0.25 \mathrm{M}$ acre-foot alternative is the lowest weighted alternative, with the least amount of physical and stakeholder preference benefit. These values are portrayed in Table 12. 
Table 12. MAVT Weights of each restoration alternative based on increases in indicator species populations in Everglades National Park and decreases in polluted discharges from Lake Okeechobee.

\begin{tabular}{|c|c|c|c|}
\hline $\begin{array}{c}\text { Reservoir Size } \\
\text { (million acre-feet) }\end{array}$ & $\begin{array}{c}\% \text { Reduced } \\
\text { Discharges from } \\
\text { Lake } \\
\text { Okeechobee }\end{array}$ & $\begin{array}{c}\text { \% Increased } \\
\text { Population of } \\
\text { Indicator Species in } \\
\text { ENP }\end{array}$ & $\begin{array}{c}\text { MAVT Index } \\
\text { (including } \\
\text { stakeholder } \\
\text { weights) }\end{array}$ \\
\hline $0.25(12 \%$ increase $)$ & $75 \%$ & $76 \%$ & 0.685 \\
\hline $0.5(25 \%)$ & $82 \%$ & $89 \%$ & 0.777 \\
\hline $1(50 \%)$ & $92 \%$ & $98 \%$ & 0.881 \\
\hline $1.5(75 \%)$ & $97 \%$ & $100 \%$ & 0.946 \\
\hline $2(100)$ & $100 \%$ & $96 \%$ & 0.987 \\
\hline
\end{tabular}

The results of the MAVT section would be further enriched and differences between alternatives made clearer with identification of the physical values of hurricane preparedness. However, the flow, water storage and discharges factors used to calculate the weights of each alternative are weighed significantly higher by Everglades restoration stakeholders. Quantifying the physical outcomes with the two unincluded factors as a result of each restoration alternative are currently under investigation by The Everglades Foundation and the South Florida Water Management District (SFWMD).

Additionally, the present version of the MAVT is based on four total criteria to measure the benefits of each restoration alternative strictly due to the potential for increased respondent inconsistency in the AHP trade-off analysis. A potentially more comprehensive version of the AHP with more criteria could be effectively tested on Everglades restoration stakeholders, but would need to be held in person or under close supervision to prevent inconsistency. The benefit of performing the AHP and in turn the MAVT using four criteria is that the AHP can be performed online, allowing for a larger amount of responses to be captured at drastically reduced costs of time, energy, and resources for stakeholders. 


\section{CHAPTER 5. CONCLUSION}

The following chapter presents the summary of the results outlined in the previous chapter, policy recommendations, potential avenues to expand upon the original framework of the survey, and knowledge gaps that could enrich the present study and others like it in the future. In short, the results of the survey outlined in the present study and the value of these results to informing Everglades restoration decision-making would be further enriched by participation from both a larger sample and wider variety of stakeholders. However, the survey does provide the groundwork for the vital process of integrating transdisciplinary strategies into Everglades restoration decision-making. Expansion of the research would ultimately contribute to the implementation of adaptive management in management of the GEE.

In summary, the present project has the potential to impact GEE restoration by providing a method for informing decision-making and providing the greatest amount of benefits to stakeholders. The AHP analysis in the present study allows a variety of stakeholders the opportunity to provide input in restoration, while also balancing power to all stakeholders despite political power and special interests. Overall, stakeholders surveyed through the survey weighed the flow of water through ENP into Florida Bay as the most important outcome of Everglades restoration, followed by reducing discharges from Lake Okeechobee into the northern estuaries, then increasing freshwater storage for a variety of human uses, and finally improving the GEE to improve hurricane preparedness.

The sample evaluated in the present study mainly includes input from the scientific community, a stakeholder group whose input has historically played a 
supporting role in decision-making (Scarlett, 2013). The results of the present study could provide input from researchers with decades of experience in the GEE to inform more scientifically based decision-making. While the initial goal of the present study was to quantify knowledge of a variety of stakeholders, researchers also represented an undersurveyed population with unique priorities and were accounted for in the survey.

The MAVT analysis in the study identified which reservoir water storage amounts in the EAA would maximize both stakeholder preferences and physical outcomes of alternative decisions. These physical outcomes were derived from ecological modeling performed by The Everglades Foundation. Using the physical outcomes of the two most important criteria to stakeholders, the EAA reservoir storage amount with the greatest benefit to the prioritized criteria was identified as the 2 million acre-foot option, followed by 1.5 million acre-foot option. The MAVT analysis would be further refined by inclusion of physical values associated with hurricanes. These values are currently being estimated by multiple ecosystem modelers in the EAA and should be available in the coming months.

Additionally, the present study involved collection of the environmental attitudes of Everglades restoration stakeholders, revealing that most stakeholders scored in the ecocentric side of the scale. Ecocentric NEP scores were surprising considering that some stakeholders may have been more prone to anthropocentric viewpoints based on interest and occupation. The results of the NEP score section of the survey have the potential to impact messaging released by environmental organizations as well as governmental organizations when facilitating multi-stakeholder conversations in the future. Surveying of additional stakeholders would likely potentially reveal more anthropocentric attitudes. 
As called for by a number of Everglades scientists, adoption of adaptive management principles is vital to improving management of the GEE (Gunderson et al., 1995; Gunderson \& Light, 2006; Ogden 2008; Scarlett, 2013). The core principles of adaptive management include management decisions informed by stakeholder input from the very beginning of the planning process (Gunderson, 2001). Due to the potential impacts of sea level rise and climate change in the GEE, management and planning of the ecosystem will likely undergo a series of changes and reimagining of timelines. While GEE restoration is certainly a daunting challenge, methods used in the present study have the potential to provide formal input from stakeholders into potential restoration decisions. The combination of social science, ecological concepts, and biological modeling guided by expert input provides a holistic strategy for decision-making in the GEE based in the values of adaptive management.

Modified replications of the study have the potential to further enrich the results and contribute more effectively to Everglades restoration decision-making. First and foremost, replication of the survey with input from a wider variety and larger quantity of stakeholders would vastly improve the holistic understanding of stakeholder preferences. The replication may be better pursued by an established, well-connected, and politically neutral organization, with the power to connect with a larger variety of stakeholders. The replication could also potentially be performed by entities such as the South Florida Ecosystem Restoration Task Force (SFERTF) or the South Florida Water Management District (SFWMD), with care not to bring political influence into decision-making. However, if the survey were distributed by larger entities, special care should be taken to include underrepresented groups discussed in previous sections of the present thesis. 
Currently, the survey used in the present thesis is still usable and can be sent to additional stakeholders. The survey should be viewed as a potential tool and work in progress with potential for increased sample size and wider variety of survey respondents in the future.

An additional replication of the survey could involve pursuit of a more traditional AHP method. Traditional AHP would involve one or a series of in-person meetings with a smaller but still representative sample of Everglades restoration stakeholders and additional criteria. Due to the increased potential for inconsistency when performing more than 6 trade-offs online, the present survey was limited to using only 4 criteria. GEE restoration is an incredibly complex undertaking with a host of additional and worthy criteria. Increasing the number of criteria also increases the total number of tradeoffs needed to complete the AHP, making in-person facilitation of decision-making critical to prevent inconsistency. Gathering of multiple stakeholders in person would also allow for facilitation of group decision-making and consensus building experiments, generating social learning and lasting relationships between ideologically opposite stakeholders. These two replications would have the potential to expand on the results of the present study, but the theoretical framework could remain the same with some expansion if desired.

Further study or continuation of the study would benefit from a few improvements in knowledge gaps. Inclusion of stakeholders would drastically improve the balance of power between stakeholder groups. Improvements in relationships and connections between stakeholder groups in the future would potentially allow for ease of contact with stakeholder groups with less influence or political power. Ecological modeling advancements would also be especially beneficial, with the addition of 
understanding of the effects of Everglades restoration on mangrove populations in conjunction with climate change and sea level rise projections.

Climate change and sea level rise has the potential to impact what is currently regarded as "successful” GEE restoration. The present study (including criteria and alternatives) could be modified over time to account for these changes in GEE restoration as climate change modeling becomes more advanced and available. As long as stakeholders are included in decision-making, adaptive management should be able to account for emerging changes in climate change knowledge and forecasting.

Finally, due to the complexity of the system and outcomes of decision-making on a wide variety of stakeholders, management of the GEE is notoriously difficult and slowmoving. As the estimated date of CERP endpoint completion extends at least an additional 20 years and estimated spending exceeds the original budget by billions of dollars, application of strategies that combine the realistic constraints of social input and scientific backing involving ecologically founded alternatives is vital. The present study represents one such study that effectively approaches decision-making with a transdisciplinary mindset. Future applications of the strategy employed in this study with input from a wider variety of stakeholders could improve the holistic power of the existing study to facilitate GEE restoration decision-making. 


\section{REFERENCES}

Alberti, M., Asbjornsen, H., Baker, L. A., Brozovic, N., Drinkwater, L. E., Drzyzga, S. A., ... \& Liu, J. (2011). Research on coupled human and natural systems (CHANS): approach, challenges, and strategies. The Bulletin of the Ecological Society of America, 92(2), 218-228.

Allen, C. R., Fontaine, J. J., Pope, K. L., \& Garmestani, A. S. (2011). Adaptive management for a turbulent future. Journal of environmental management, 92(5), $1339-1345$.

Ananda, J., \& Herath, G. (2003). The use of Analytic Hierarchy Process to incorporate stakeholder preferences into regional forest planning. Forest policy and economics, 5(1), 13-26.

Anderson, D. L., \& Flaig, E. G. (1995). Agricultural best management practices and surface water improvement and management. Water Science and Technology, 31(8), 109-121.

Arnette, A., Zobel, C., Bosch, D., Pease, J., \& Metcalfe, T. (2010). Stakeholder ranking of watershed goals with the vector analytic hierarchy process: Effects of participant grouping scenarios. Environmental Modelling \& Software, 25(11), 1459-1469.

Bancroft, G. T., Ogden, J. C., \& Patty, B. W. (1988). Wading bird colony formation and turnover relative to rainfall in the Corkscrew Swamp area of Florida during 1982 through 1985. The Wilson Bulletin, 50-59.

Barnes, T. (2005). Caloosahatchee Estuary conceptual ecological model. Wetlands, 25(4), 884.

Barone, S., Errore, A., \& Lombardo, A. (2014). Prioritisation of alternatives with analytical hierarchy process plus response latency and web surveys. Total Quality Management \& Business Excellence, 25(7-8), 953-965.

Bloetscher, F., Heimlich, B. N., \& Romah, T. (2011). Counteracting the effects of sea level rise in Southeast Florida. Journal of Environmental Science and Engineering, 5(11).

Brown, C. E., Bhat, M. G., Rehage, J. S., Mirchi, A., Boucek, R., Engel, V., ... \& Sukop, M. (2018). Ecological-economic assessment of the effects of freshwater flow in the Florida Everglades on recreational fisheries. Science of the Total Environment, 627, 480-493. 
Buysse, K., \& Verbeke, A. (2003). Proactive environmental strategies: A stakeholder management perspective. Strategic management journal, 24(5), 453-470.

Carter, N., Viña, A., Hull, V., McConnell, W., Axinn, W., Ghimire, D., \& Liu, J. (2014). Coupled human and natural systems approach to wildlife research and conservation. Ecology and Society, 19(3).

Cattelino, J. R. (2009). Florida Seminoles and the Cultural Politics of the Everglades. IAS Occasional Paper.

Catton Jr, W. R., \& Dunlap, R. E. (1980). A new ecological paradigm for post-exuberant sociology. American behavioral scientist, 24(1), 15-47.

Cheng, C. H. (1997). Evaluating naval tactical missile systems by fuzzy AHP based on the grade value of membership function. European Journal of Operational Research, 96(2), 343-350.

Contreras, F., Hanaki, K., Aramaki, T., \& Connors, S. (2008). Application of analytical hierarchy process to analyze stakeholders preferences for municipal solid waste management plans, Boston, USA. Resources, Conservation and Recycling, 52(7), 979-991.

Czajkowski, J., Engel, V., Martinez, C., Mirchi, A., Watkins, D., Sukop, M. C., \& Hughes, J. D. (2018). Economic impacts of urban flooding in South Florida: Potential consequences of managing groundwater to prevent salt water intrusion. Science of the Total Environment, 621, 465-478.

D’Adamo, I., Falcone, P. M., \& Morone, P. (2019). Assessing the transition towards bioeconomy through a socio-economic indicator.

De Lange, W. J., Stafford, W. H., Forsyth, G. G., \& Le Maitre, D. C. (2012). Incorporating stakeholder preferences in the selection of technologies for using invasive alien plants as a bio-energy feedstock: Applying the analytical hierarchy process. Journal of environmental management, 99, 76-83.

Dessu, S. B., Price, R. M., Troxler, T. G., \& Kominoski, J. S. (2018). Effects of sea-level rise and freshwater management on long-term water levels and water quality in the Florida Coastal Everglades. Journal of environmental management, 211, 164176.

Dodgson, J. S., Spackman, M., Pearman, A., \& Phillips, L. D. (2009). Multi-criteria analysis: a manual.

Drengson, A. R. (1980). Shifting paradigms: From the technocratic to the personplanetary. Environmental Ethics, 2(3), 221-240. 
Du, Y., Wang, X., Zhang, L., Feger, K. H., Popp, J., \& Sharpley, A. (2019). Multistakeholders' preference for best management practices based on environmental awareness. Journal of Cleaner Production, 236, 117682.

Duke, J. M., \& Aull-Hyde, R. (2002). Identifying public preferences for land preservation using the analytic hierarchy process. Ecological Economics, 42(1-2), 131-145.

Dunlap, R. E. (2008). The new environmental paradigm scale: From marginality to worldwide use. The Journal of environmental education, 40(1), 3-18.

Dunlap, R. E., \& Van Liere, K. D. (1978). The "new environmental paradigm". The journal of environmental education, 9(4), 10-19.

Dunlap, R. E., Van Liere, K. D., Mertig, A. G., \& Jones, R. E. (2000). New trends in measuring environmental attitudes: measuring endorsement of the new ecological paradigm: a revised NEP scale. Journal of social issues, 56(3), 425-442.

Dussias, A. M. (2013). The Seminole Tribe of Florida and the Everglades Ecosystem: Refuge and Resources. FIU L. Rev., 9, 227.

Finkl, C. W., \& Makowski, C. (2017). The Florida Everglades: an overview of alteration and restoration. In Coastal Wetlands: Alteration and Remediation (pp. 3-45). Springer, Cham.

Fishburn, P. C. (1967). Methods of estimating additive utilities. Management science, 13(7), 435-453.

Florida Department of Environmental Protection (FDEP). (2019). Everglades Forever Act (EFA). Retrieved from: https://floridadep.gov/eco-pro/ecopro/content/everglades-forever-act-efa.

Glicken, J. (2000). Getting stakeholder participation 'right': a discussion of participatory processes and possible pitfalls. Environmental Science \& Policy, 3(6), 305-310.

Grunwald, M. (2006). The swamp: The Everglades, Florida, and the politics of paradise. Simon and Schuster.

Gunderson, L. H. (2001). Panarchy: understanding transformations in human and natural systems. Island press.

Gunderson, L. H., Light, S. S., \& Holling, C. S. (1995). Lessons from the Everglades. BioScience, 45, S66-S73. 
Gunderson, L., \& Light, S. S. (2006). Adaptive management and adaptive governance in the everglades ecosystem. Policy Sciences, 39(4), 323-334.

Hackney, C. T. (2000). Restoration of coastal habitats: expectation and reality. Ecological Engineering, 15(3-4), 165-170.

Haigh, I. D., Wahl, T., Rohling, E. J., Price, R. M., Pattiaratchi, C. B., Calafat, F. M., \& Dangendorf, S. (2014). Timescales for detecting a significant acceleration in sea level rise. Nature Communications, 5, 3635.

Havens, K. E., \& Gawlik, D. E. (2005). Lake Okeechobee conceptual ecological model. Wetlands, 25(4), 908-925.

Hawcroft, L. J., \& Milfont, T. L. (2010). The use (and abuse) of the new environmental paradigm scale over the last 30 years: A meta-analysis. Journal of Environmental psychology, 30(2), 143-158.

Heikkila, T., \& Gerlak, A. K. (2005). The formation of large-scale collaborative resource management institutions: Clarifying the roles of stakeholders, science, and institutions. Policy Studies Journal, 33(4), 583-612.

Herath, G. (2004). Incorporating community objectives in improved wetland management: the use of the analytic hierarchy process. Journal of environmental management, 70(3), 263-273.

Holling, C. S. (2017). Adaptive environmental assessment and management.

Hostmann, M., Bernauer, T., Mosler, H. J., Reichert, P., \& Truffer, B. (2005). Multiattribute value theory as a framework for conflict resolution in river rehabilitation. Journal of Multi-Criteria Decision Analysis, 13(2-3), 91-102.

Huang, I. B., Keisler, J., \& Linkov, I. (2011). Multi-criteria decision analysis in environmental sciences: ten years of applications and trends. Science of the total environment, 409(19), 3578-3594.

Jamal, T., Urmee, T., Shafiullah, G. M., \& Shahnia, F. (2018, October). Using Experts' Opinions and Multi-Criteria Decision Analysis to Determine the Weighing of Criteria Employed in Planning Remote Area Microgrids. In 2018 International Conference and Utility Exhibition on Green Energy for Sustainable Development (ICUE) (pp. 1-7). IEEE.

Kaltenborn, B. P., Andersen, O., \& Nellemann, C. (2009). Amenity development in the Norwegian mountains: Effects of second home owner environmental attitudes on preferences for alternative development options. Landscape and Urban Planning, 91(4), 195-201. 
Keeney, R. L., \& Raiffa, H. (1993). Decisions with multiple objectives: preferences and value trade-offs. Cambridge university press.

Kiker, G. A., Bridges, T. S., Varghese, A., Seager, T. P., \& Linkov, I. (2005). Application of multicriteria decision analysis in environmental decision making. Integrated environmental assessment and management, 1(2), 95-108.

Kilbourne, W. E., Beckmann, S. C., \& Thelen, E. (2002). The role of the dominant social paradigm in environmental attitudes: A multinational examination. Journal of business Research, 55(3), 193-204.

Koebel Jr, J. W., \& Bousquin, S. G. (2014). The Kissimmee River restoration project and evaluation program, Florida, USA. Restoration Ecology, 22(3), 345-352.

Kortenkamp, K. V., \& Moore, C. F. (2001). Ecocentrism and anthropocentrism: Moral reasoning about ecological commons dilemmas. Journal of Environmental Psychology, 21(3), 261-272.

Light, A. R. (2010). Reducing Nutrient Pollution in the Everglades Agricultural Area through best management practices. Nat. Resources \& Env't, 25, 26.

Light, S. S., \& Dineen, J. W. (1994). Water control in the Everglades: a historical perspective. Everglades: The ecosystem and its restoration, 5, 47-84.

Linkov, I., \& Moberg, E. (2011). Multi-criteria decision analysis: environmental applications and case studies. CRC Press.

Liu, J., Dietz, T., Carpenter, S. R., Alberti, M., Folke, C., Moran, E., ... \& Ostrom, E. (2007). Complexity of coupled human and natural systems. science, 317(5844), 1513-1516.

Mardle, S., Pascoe, S., \& Herrero, I. (2004). Management objective importance in fisheries: an evaluation using the analytic hierarchy process (AHP).

Environmental Management, 33(1), 1-11.

Mateo, J. R. S. C. (2012). Multi-criteria analysis. In Multi criteria analysis in the renewable energy industry (pp. 7-10). Springer, London.

Mather Economics. (2010). Measuring the Economic Benefits of America's Everglades Restoration. Palmetto Bay, FL: Study Prepared for The Everglades Foundation.

Mathiyazhagan, K., Govindan, K., \& Noorul Haq, A. (2014). Pressure analysis for green supply chain management implementation in Indian industries using analytic hierarchy process. International Journal of Production Research, 52(1), 188-202. 
Mavrommati, G., Bithas, K., Borsuk, M. E., \& Howarth, R. B. (2016). Integration of ecological-biological thresholds in conservation decision making. Conservation biology, 30(6), 1173-1181.

McLean, A. R., Ogden, J. C., \& Williams, E. E. (2002). Comprehensive Everglades Restoration Plan.

Milon, J. W., \& Scrogin, D. (2006). Latent preferences and valuation of wetland ecosystem restoration. Ecological Economics, 56(2), 162-175.

Montague, C. L., \& Ley, J. A. (1993). A possible effect of salinity fluctuation on abundance of benthic vegetation and associated fauna in northeastern Florida Bay. Estuaries, 16(4), 703-717.

National Research Council. (2003). Adaptive monitoring and assessment for the comprehensive Everglades restoration plan. National Academies Press.

Noy, C. (2008). Sampling knowledge: The hermeneutics of snowball sampling in qualitative research. International Journal of social research methodology, 11(4), 327-344.

Nungesser, M., Saunders, C., Coronado-Molina, C., Obeysekera, J., Johnson, J., McVoy, C., \& Benscoter, B. (2015). Potential effects of climate change on Florida's Everglades. Environmental management, 55(4), 824-835.

Nuttle, W. K., Fourqurean, J. W., Cosby, B. J., Zieman, J. C., \& Robblee, M. B. (2000). Influence of net freshwater supply on salinity in Florida Bay. Water Resources Research, 36(7), 1805-1822.

Ogden, L. (2008). The Everglades ecosystem and the politics of nature. American Anthropologist, 110(1), 21-32.

Orduño Torres, M. A., Kallas, Z., Ornelas Herrera, S. I., \& Guesmi, B. (2019). Is Technical Efficiency Affected by Farmers' Preference for Mitigation and Adaptation Actions against Climate Change? A Case Study in Northwest Mexico. Sustainability, 11(12), 3291.

Pearlstine, L. G., Pearlstine, E. V., \& Aumen, N. G. (2010). A review of the ecological consequences and management implications of climate change for the Everglades. Journal of the North American Benthological Society, 29(4), 15101526.

Perry, W. (2004). Elements of south Florida's comprehensive Everglades restoration plan. Ecotoxicology, 13(3), 185-193. 
Perry, W. B. (2008). Everglades restoration and water quality challenges in south Florida. Ecotoxicology, 17(7), 569.

Qureshi, M. E., \& Harrison, S. R. (2001). A decision support process to compare riparian revegetation options in Scheu Creek catchment in North Queensland. Journal of Environmental Management, 62(1), 101-112.

Qureshi, M. E., \& Harrison, S. R. (2003). Application of the analytic hierarchy process to riparian revegetation policy options. Small-scale forest economics, management and policy, 2(3), 441.

Reed, M. S. (2008). Stakeholder participation for environmental management: a literature review. Biological conservation, 141(10), 2417-2431.

Rideout, B. E. (2005). The effect of a brief environmental problems module on endorsement of the new ecological paradigm in college students. The Journal of Environmental Education, 37(1), 3-11.

Rideout, B. E., Hushen, K., McGinty, D., Perkins, S., \& Tate, J. (2005). Endorsement of the new ecological paradigm in systematic and e-mail samples of college students. The Journal of Environmental Education, 36(2), 15-23.

Rodgers, L., Bodle, M., Black, D., Laroche, F., Pratt, P., \& Boughton, A. (2012). Status of nonindigenous species. 2012 South Florida Environmental Report, 1, 7-35.

Saaty, T. L. (1978). Modeling unstructured decision problems - the theory of analytical hierarchies. Mathematics and computers in simulation, 20(3), 147-158.

Saaty, T. L. (1981). Decision Making for leaders: The analytical hierarchy process for decisions in a complex world. Lifetime Learning Publications.

Saaty, T. L. (1990). How to make a decision: the analytic hierarchy process. European journal of operational research, 48(1), 9-26.

Saaty, T. L., \& Vargas, L. G. (2012). Models, methods, concepts \& applications of the analytic hierarchy process (Vol. 175). Springer Science \& Business Media.

Scarlett, L. (2013). Collaborative adaptive management: challenges and opportunities. Ecology and Society, 18(3).

Schmoldt, D., Kangas, J., Mendoza, G. A., \& Pesonen, M. (Eds.). (2013). The analytic hierarchy process in natural resource and environmental decision making (Vol. 3). Springer Science \& Business Media. 
Seleman, A and M. G. Bhat. "Multi-Criteria Assessment of Sanitation Technologies in Rural Tanzania: Implications for Program Implementation, Health and SocioEconomic Improvements." Technology in Society, Technology in Society, 46 (2016), p. 70-79.

Sime, P. (2005). St. Lucie estuary and Indian River Lagoon conceptual ecological model. Wetlands, 25(4), 898.

Sklar, F. H., Chimney, M. J., Newman, S., McCormick, P., Gawlik, D., Miao, S., ... \& Crozier, G. (2005). The ecological-societal underpinnings of Everglades restoration. Frontiers in Ecology and the Environment, 3(3), 161-169.

Smith, S. K. (2005). Florida population growth: Past, present and future. Bureau of Economic and Business Research, University of Florida, Gainesville.

Snyder, G. H., \& Davidson, J. M. (1994). Everglades agriculture: past, present, and future. Everglades: The ecosystem and its Restoration, 85-115.

South Florida Water Management District (SFWMD). (2019). Quick Facts and Figures. Retrieved from: https:/www.sfwmd.gov/who-we-are/facts-and-figures.

Stainback, G. A., Fedler, T., Davis, S. E., \& KC, B. (2018). Recreational Fishing in Florida Bay: Economic Significance and Angler Perspectives. Tourism in Marine Environments.

Stern, P. C., Dietz, T., \& Guagnano, G. A. (1995). The new ecological paradigm in social-psychological context. Environment and behavior, 27(6), 723-743.

Toth, L. A. (1993). The ecological basis of the Kissimmee River restoration plan. Florida Scientist, 25-51.

Triantaphyllou, E. (2000). Multi-criteria decision making methods. In Multi-criteria decision making methods: A comparative study (pp. 5-21). Springer, Boston, MA.

US Army Corps of Engineers and South Florida Water Management District (1999). Central and Southern Florida Project Comprehensive Review Study, Final Integrated Feasibility Report and Programmatic Environmental Impact Statement. United States Army Corps of Engineers, Jacksonville District, Jacksonville, FL, and South Florida Water Management District, West Palm Beach, FL.

Watson, T. A., Werner, A. D., \& Simmons, C. T. (2010). Transience of seawater intrusion in response to sea level rise. Water Resources Research, 46(12). 
White, W., \& Borchers, A. (2016). Motivation behind reshoring decisions in manufacturing. Operations and Supply Chain Management: An International Journal, 9(3), 205-209.

Wolf, D., \& Klaiber, H. A. (2017). Bloom and bust: Toxic algae's impact on nearby property values. Ecological economics, 135, 209-221.

Zahedi, F. (1986). The analytic hierarchy process - a survey of the method and its applications. interfaces, 16(4), 96-108. 